\title{
Characterization of the ECN spray $A$ in different facilities. Part 1: boundary conditions characterization
}

Moez Ben Houidi ${ }^{1,2,}$, Camille Hespel ${ }^{3}$, Michele Bardi ${ }^{4}$, Ob Nilaphai $^{3}$, Louis-Marie Malbec $^{4}$, Julien Sotton $^{2}$, Marc Bellenoue ${ }^{2}$, Camille Strozzi ${ }^{2}$, Hugo Ajrouche ${ }^{3}$, Fabrice Foucher ${ }^{3}$, Bruno Moreau ${ }^{3}$, Christine Rousselle ${ }^{3}$, and Gilles Bruneaux ${ }^{4}$

\footnotetext{
${ }^{1}$ King Abdullah University of Science and Technology (KAUST), CCRC, PSE, 23955-6900 Thuwal, Saudi Arabia

${ }^{2}$ Institut PPRIME, CNRS, ISAE-ENSMA, Université de Poitiers, Département Fluide Thermique Combustion, BP 40109, Teleport 2, 1 avenue Clement Ader, 86962 Futuroscope Chasseneuil-du-Poitou Cedex, France

${ }^{3}$ Univ. Orléans, INSA-CVL, PRISME, EA 4229, 45072 Orléans, France

${ }^{4}$ IFP Energies nouvelles, 1 et 4 avenue de Bois Préau, 92852 Rueil-Malmaison, France; Institut Carnot IFPEN Transports Energie
}

Received: 13 September 2019 / Accepted: 31 March 2020

\begin{abstract}
The Engine Combustion Network (ECN) community has greatly contributed to improve the fundamental understanding of spray atomization and combustion at conditions relevant to internal combustion engines. In this context, standardized spray experiments have been defined to facilitate the comparison of experimental and simulation studies performed in different facilities and with different models. This operating mode promotes collaborations among research groups and accelerates the advancement of research on spray. In efforts to improve the comparability of the ECN spray A experiments, it is of high importance to review the boundary conditions of different devices used in the community. This work is issued from the collaboration in the ECN France project, where two new experimental facilities from PPRIME (Poitiers) and PRISME (Orleans) institutes are validated to perform spray A experiments. The two facilities, based on Rapid Compression Machine (RCM) design, have been investigated to characterize their boundary conditions (e.g., flow velocity as well as fuel and gas temperatures). A set of standardized spray experiments were performed to compare their results with those obtained in other facilities, in particular the Constant Volume Pre-burn (CVP) vessel at IFPEN. It is noteworthy that it is the first time that RCM type facilities are used in such a way within the ECN. This paper (part 1) focuses on the facilities description and the fine characterization of their boundary conditions. A further paper (part 2) will present the results obtained with the same facilities performing ECN standard spray A characterizations. The reported review of thermocouple thermometry highlights that it is necessary to use thin-wires and bare-bead junction as small as possible. This would help to measure the temperature fluctuations with a minimal need for error corrections, which are highly dependent on the proper estimation of the velocity through the junction, and therefore it may introduce important uncertainties. Temperature heterogeneities are observed in all spray A devices. The standard deviation of the temperature distribution at the time of injection is approximately $5 \%$. We report time-resolved temperature measurement from PPRIME RCM, performed in the near nozzle area during the injection. In inert condition, colder gases from the boundary layer are entrained toward the mixing area of the spray causing a further deviation from the target temperature. This emphasizes the importance of the temperature in the boundary (wall) layer. In reacting condition, the temperature of these entrained gases increases by the effect of the increased pressure, as the RCM has a relatively small volume. Generally, the velocity and turbulence levels are an order of magnitude higher in RCM and constant pressure flow compared to CVP vessels. The boundary characterization presented here will be the base for discussing spray behavior in the part 2 of this paper.
\end{abstract}

\section{Introduction}

The Engine Combustion Network (ECN) [1] has greatly contributed to accelerate the research efforts focused on

\footnotetext{
* Corresponding author: moez. benhouidi@kaust.edu.sa
}

spray atomization and combustion in both Diesel and direct injection engines. In this context, experimental and simulation works are joined in a complementary way to improve our understanding of the complex physical and chemical phenomena taking place in fuel injection and combustion process. The efforts from the experimental side are 
intended to provide a robust and accurate database for model validation, and therefore the boundary conditions need to be accurately characterized. To this end, spray A reference condition has been defined to provide a detailed list of boundary conditions. The conformity of the experimental apparatus employed to these boundary conditions has been discussed in different publications for the first institutions participating to ECN [2-4]. The analysis of the results indicated that some discrepancies in the spray results are caused by different boundary conditions between these facilities. Other effects related to injector nozzle geometry [5-7] and to aging [8] have been extensively studied. The boundary conditions of Constant Pressure Flow $(\mathrm{CPF})$ and Constant Volume Pre-burn (CVP) vessels used for spray A studies have been reviewed in [3]. The work reported a detailed comparison of the following facilities: the CPF of CMT [9], the CPF of Spray Combustion Laboratory (SCL) in Caterpillar, the CVP of IFPEN, Sandia National Laboratories (SNL) [2], Technical University of Eindhoven (TUE) [10], and Michigan Technological University (MTU) [11, 12]. The review in [3] concluded that the ambient gas was relatively homogeneous in $\mathrm{CPF}$ compared to CVP. Nevertheless, differences among the CVP were highlighted through the comparison of the bulk temperature $T_{\text {bulk }}$ (defined as the average homogeneous temperature) with the actual measured temperature (called $\left.T_{\text {core }}\right)$. Different ratios of $T_{\text {core }} / T_{\text {bulk }}$ were observed in these facilities and this demonstrated that the heat losses to the walls were different from one vessel to another. These ratios were easily correlated to the gas mixing intensity controlled by the CVP fan speed. The injector nozzle temperature, which is representative of the fuel temperature, was also pointed out in [3] as an important boundary parameter. It has been demonstrated that the liquid length and the soot formation are highly sensitive to this parameter [3, 9, 13]. Thus, many efforts were dedicated in the ECN community to standardize the measurement of the temperature in the injector nozzle. A dummy injector instrumented with a sensitive thermocouple located in the sac area was proposed for this purpose. This tool helped to optimize the cooling of the injectors in the CPF and CVP vessels. As a result, the fuel temperature in these facilities was on the target within $\pm 15 \mathrm{~K}$ [3]. In CVP vessels, major and minor products are generated in the post-burn stage. Several studies [3, 13, 14] pointed out the potential effects of these species on the spray ignition, lift-off length and the soot oxidation.

Few studies [15-17] have reported ambient velocity measurement in ECN facilities. In spray A target conditions, a near quiescent ambient gas is required and is fulfilled if the global velocity in the vessel is lower than $1 \mathrm{~m} / \mathrm{s}$. This threshold has been chosen for two reasons: (i) this value is significantly lower than the velocities of the spray entrained gases, (ii) lower values are hard to achieve in CVP and CPF, otherwise the temperature homogeneity is too deteriorated. Still, recent studies [13, 18, 19] have pointed the sensitivity of the spray to possible different turbulence levels.

ECN-France is an Agence Nationale de la Recherche (ANR) founded project with the goal of involving French research centers (PPRIME institute in Poitiers and
PRISME institute in Orleans) to contribute to ECN database. To this end, an extensive campaign has been carried out to characterize their experimental facilities to meet the ECN spray A conditions. IFPEN led this project by providing assistance on the experimental methodologies and by characterizing all the injectors in their wellcharacterized CVP. Thus, the experimental data from IFPEN have been used as reference data for comparison.

This work has been conducted in two phases: (i) characterize in details the boundary conditions and, (ii) perform measurement at spray A conditions using the reference diagnostics that are standardized in ECN community [4]. The present paper (part 1) presents the results obtained in the first phase, while the second is discussed in a further publication (part 2) [20].

More in details, the current paper reviews the characterization of the boundary conditions in spray A experiments with focus on the ambient temperature and velocity measurements. Particularly, it introduces two new vessels that have been used to study spray A during the ECN France project. The Rapid Compression Machine (RCM) of PPRIME institute and the New One Shot Engine (NOSE) of PRISME institute are presented and compared to the CVP of IFPEN in which all the injectors used were first characterized. The target conditions tested are the reference spray A conditions for inert $\left(\mathrm{O}_{2} 0 \%\right)$ and reactive conditions $\left(\mathrm{O}_{2} 15 \%\right.$ vol $)$ [1]. The boundary conditions characterization will be the base for the discussion of the spray results that will be presented in the part 2 of this paper [20] in an approach similar to that of [4].

In the first part of this paper, we describe the new RCM vessels used for the spray A experimental studies and we compare them to the IFPEN CVP. In a second step, we present Particle Image Velocimetry (PIV) measurements focused on the Start Of Injection (SOI) and we compare the results with the data available in the literature. Later, we review the temperature measurements in ECN facilities with a quick overview on optical methods that can be of potential interest. We also review thin-wire thermocouple thermometry, as it was widely used for the measurement of ambient gas temperature in previous spray A studies. We present the temperature distributions of current vessels and compare them to those of CPF and CVP reported in literature. We also report time-resolved temperature measurement in the near nozzle area during the injection. In the remnant of this work, for the sake of simplicity, we may refer to the experimental facility of each institution by the name of the institution itself (e.g., instead of "in the rapid compression machine at PPRIME", "in PPRIME').

\section{Experimental setups}

In this section, the specific features of the experimental facilities employed by the different institutions are presented. Since the description of IFPEN facility can be found in the literature $[2,3,8]$, only a general description is presented in this work. On the other hand, more attention will 
(a)

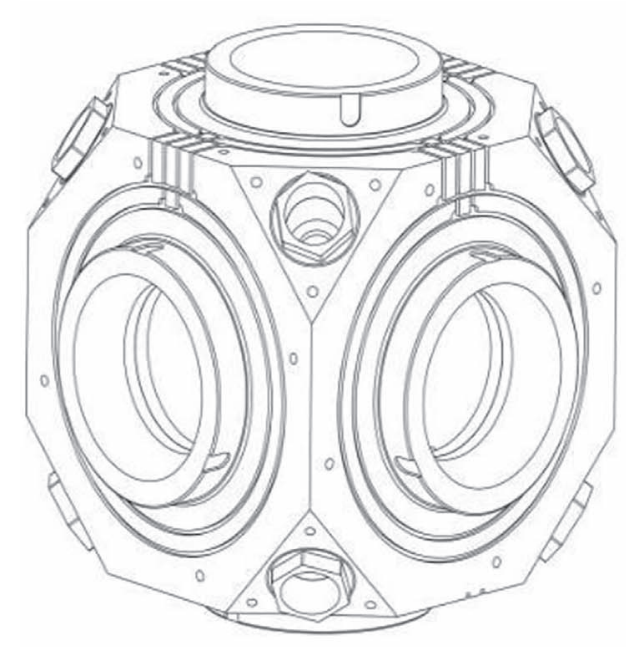

(b)

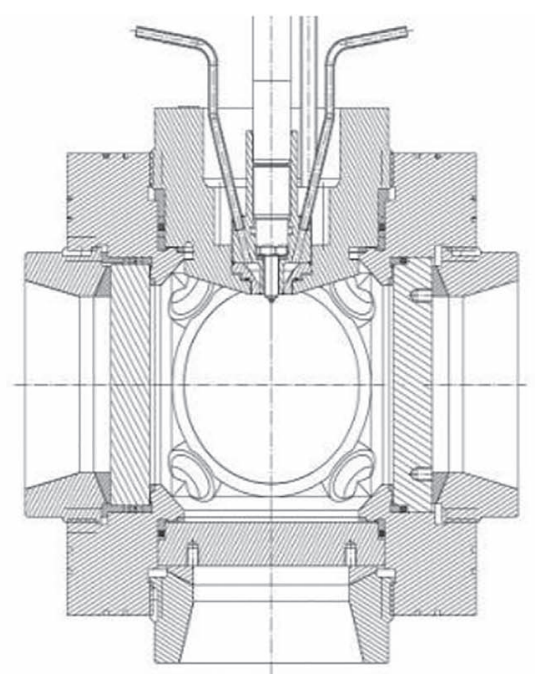

Fig. 1. (a) 3D view and (b) cross section of IFPEN CVP.

be given to the PPRIME and PRISME facilities, being their standardization the main objective of this paper.

\subsection{IFPEN}

The IFPEN CVP vessel has been previously presented and compared to other CPF and CVP vessels in [2, 3]. The layout of the chamber is presented in Figure 1. The vessel operation has already been extensively described in [3] and it is only briefly summarized here. In a pre-burn constant volume vessel, the fuel is injected in a chamber whose pressure, density, and temperature are representative of the thermodynamic conditions encountered in the combustion chamber of a real engine at the injection timing. This requires the ability to reach high temperatures and density, which are achieved by the combustion of a flammable mixture, generally referred as "pre-burn". The experimental methodology can be summarized in four main phases:

(i) Sequential gas filling: the chamber is filled with the pre-burn gases in precise proportions.

(ii) Pre-burn: a premixed combustion is triggered by a spark plug to increase the temperature and the pressure of the gas. The product composition (e.g., $\mathrm{O}_{2}$ content) is the experiment target value.

(iii) Cool down: the heat flux towards the walls decreases progressively the gas temperature and pressure.

(iv) Injection: when the gases reach the target temperature, the fuel is injected.

It is important to underline that the time scale of the injection $(\sim 1.5 \mathrm{~ms})$ is short compared to the cool down time scale $(2-3 \mathrm{~s})$. Therefore, the pressure and the temperature can be assumed constant during the injection event. The details of these phases are presented in $[2,8]$.

\subsection{PPRIME}

In PPRIME, a flat piston RCM is used for the study of ECN spray A. This device was previously used to study auto-ignition phenomena. More details about its standard configuration can be found in [21-24]. The schematic of the RCM is shown in Figure 2. PPRIME RCM performs a single shot experiment in two steps:

(i) Rapid compression of approximately $35 \mathrm{~ms}$ (approximately $1050 \mathrm{~cm}^{3}$ displacement and a CR of 9:1).

(ii) Constant volume stage of approximately $500 \mathrm{~ms}$.

When controlling the initial gas temperature, pressure and composition, a wide range of conditions can be achieved at the end of compression while the volume is kept constant.

The RCM has optical access to the entire volume at TDC without any distortion, thus facilitating the use of optical diagnostics techniques. The ECN injector (\#306.14) is centrally mounted on the upper side of the RCM. The same side is also equipped with: (i) a cartridge heater having an integrated thermocouple, (ii) an intake/ exhaust valve and (iii) a Kistler 6125 piezoelectric pressure sensor. Three of the four lateral sides are equipped with Sapphire windows. The entire RCM cylinder body is covered with Watlow Silicon rubber heaters. All heaters are controlled to reach an initial gas temperature of $363 \mathrm{~K}$. The injector is connected to a GM 97303659 rail through a $24 \mathrm{~cm}$ length high-pressure tube while the fuel return line is connected to a TESCOM 44-1700 backpressure regulator. A Kistler 4067E fuel pressure sensor is installed at $7 \mathrm{~cm}$ from the injector inlet. The fuel is pressurized using a Maximator GSF300 hydro-pneumatic pump. The RCM settings used to reach the ECN spray A test conditions are summarized later in Table 1. The flat piston used in the current RCM configuration is known to generate substantial temperature heterogeneities caused by the internal aerodynamics $[23,25]$. The piston cylinder motion generates roll-up vortices that mixe the cold boundary layer with the warmer bulk gas. At the end of the compression, the piston stops at the TDC and the vortices get smaller by the effect of viscous dissipation, while making the gas 


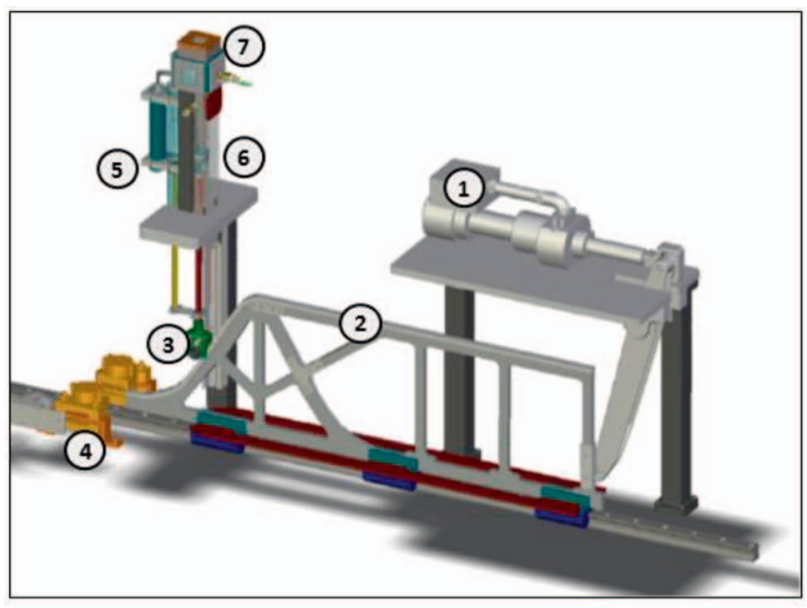

(a)

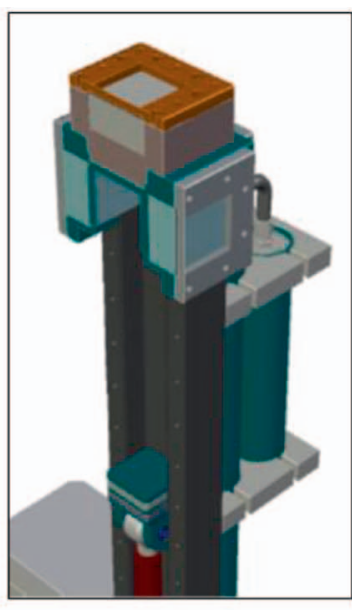

(b)

Fig. 2. Schematic of PPRIME institute RCM. (a) General view: (1) hydraulic cylinder, (2) cam, (3) guiding wheel, (4) brake system, (5) return pneumatic cylinder, (6) piston/cylinder, (7) combustion chamber. (b) Zoomed section view on the piston cylinder assembly.

Table 1. Comparison of IFPEN, PPRIME, and PRISME vessels when set for spray A experiments.

\begin{tabular}{lccc}
\hline & IFPEN & PPRIME & PRISME \\
\hline Vessel & $\mathrm{CVP}$ & $\mathrm{RCM}$ & NOSE $(\mathrm{RCM})$ \\
Volume at SOI $\left(\mathrm{cm}^{3}\right)$ & 1400 & 131 & $\sim 240$ \\
Displacement & - & $1050 \mathrm{~cm}^{3}$ & $3354 \mathrm{~cm}^{3}$ \\
Compression ratio & - & $9: 1$ & $15: 1$ \\
Injector mounting & Center side window & Center upper window & Center upper window \\
Injector tip protrusion from wall $(\mathrm{mm})$ & 3 & 4 & 4 and 6 \\
Gas composition at SOI: inert $(\% \mathrm{~mol})$ & $\mathrm{N}_{2} / \mathrm{CO}_{2} / \mathrm{H}_{2} \mathrm{O}: 88.5 / 9.3 / 2.2$ & $\mathrm{~N}_{2} /$ Ar: $58 / 42$ & $\mathrm{~N}_{2}: 100$ \\
Gas composition at SOI: reactive $(\% \mathrm{~mol})$ & $\mathrm{O}_{2} / \mathrm{N}_{2} / \mathrm{CO}_{2} / \mathrm{H}_{2} \mathrm{O}:$ & $\mathrm{O}_{2} / \mathrm{N}_{2} / \mathrm{Ar}: 15 / 40 / 45$ & $\mathrm{O}_{2} / \mathrm{N}_{2}: 15 / 85$ \\
& $15 / 73.5 / 9.3 / 2.2$ & & 1.14 \\
Heat capacity $\mathrm{C}_{\mathrm{p}}$ at SOI $(\mathrm{kJ} / \mathrm{kg} \mathrm{K})$ & 1.21 & 0.89 & Premixed \\
Gas fill & Sequential & Premixed & 373 \\
Wall/body temperature $(\mathrm{K})$ & 473 & 363 & Rectangular \\
Optical access & Cylindrical & Square & $80 \times 25 \mathrm{~mm}^{2}$ \\
Window size & 80 mm diameter & $50 \times 50 \mathrm{~mm}^{2}$ & 4 \\
Number of optical access & 5 & 3 & 306.19 \\
Injector \# & 306.15 & 306.14 & \\
\hline
\end{tabular}

temperature more homogeneous. Thus, the injection is placed later in the post-compression period (approximately $74 \mathrm{~ms}$ after TDC) to allow reaching a reasonably homogeneous and quiescent flow as required for the ECN spray A conditions. A typical RCM pressure profile is illustrated in Figure 3. At inert conditions $\left(\mathrm{O}_{2} \mathrm{~mol} \%=0\right)$, the comparison of cases with and without injections shows how the evaporated spray cools down the temperature inside the chamber as the in-cylinder pressure decreases after the injection. At reactive conditions $\left(\mathrm{O}_{2} \mathrm{~mol} \%=15\right)$, the spray combustion induces a significant pressure rise of approximately $10 \mathrm{bar}$. The relatively small volume of the RCM chamber $\left(131 \mathrm{~cm}^{3}\right.$ at TDC) explains this pressure increase. The ambient gas temperature was measured with thin wires $(7.6 \mu \mathrm{m})$ type $\mathrm{K}$ thermocouples and using a pre-calibrated acquisition system (QuickDAQ DT9805). According to the hardware manufacturer, this device is capable of recording the junction temperature at 


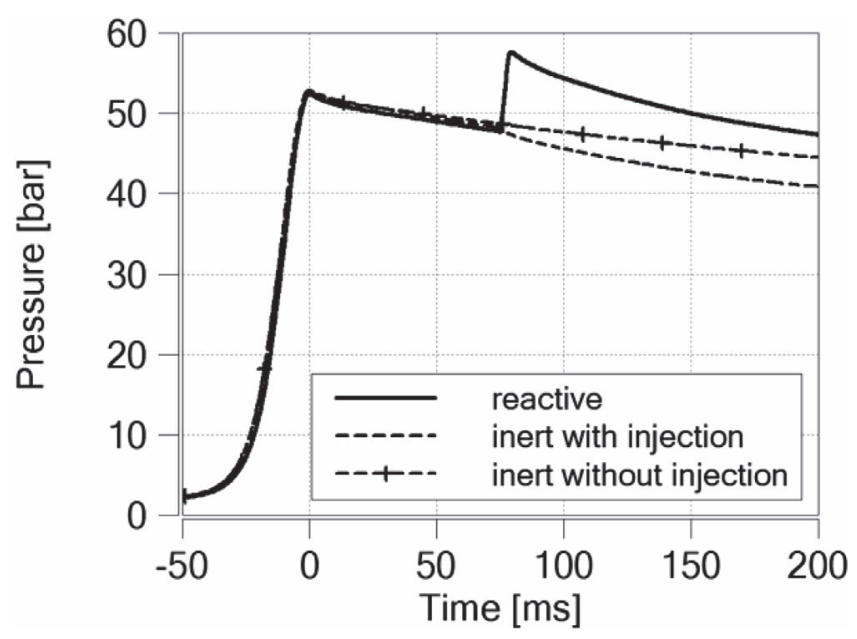

Fig. 3. Typical pressure profile of inert and reactive conditions at spray A conditions in PPRIME.

a sampling rate of $10 \mathrm{kHz}$ with an accuracy of $0.2 \mathrm{~K}$. The thermocouple wires used have a high purity level that meet the type $\mathrm{K}$ standard, which has an error level of $\pm 1 \mathrm{~K}$. Further details about the measurement technique and the calculation of the gas temperature are reported later in Section 4.2.4.

\subsection{PRISME}

The experimental apparatus at PRISME is referred to as New One Shot Engine (NOSE). It was developed based on the Rapid Cycling Machine (RCYM) concept. This facility is designed to study the combustion at conditions relevant to recent Compression Ignition (CI) engines. A single-cylinder low-speed diesel engine (standard power: $13.4 \mathrm{~kW}$ at $750 \mathrm{rpm}$ ) is used as shown in Figure 4a. The engine displacement volume is $3354 \mathrm{~cm}^{3}$ (the bore and stroke are respectively $155 \mathrm{~mm}$ and $177.8 \mathrm{~mm}$ ) and the $\mathrm{CR}$ is $15: 1$. The original cylinder head is replaced with a customized optical chamber equipped with four quartz windows (25 mm thick, $25 \mathrm{~mm}$ wide, and $80 \mathrm{~mm}$ long). Different cross-section views of this chamber are presented in Figures $4 \mathrm{~b}-4 \mathrm{~d}$. The chamber has a rectangular prism shape of $44 \times 44 \times 90 \mathrm{~mm}$ length $\left(240 \mathrm{~cm}^{3}\right.$ total volume). The ECN injector (\#306.19 [8]) is centrally mounted on the upper side. The piston head is designed to achieve a nearquiescent gas condition at the top dead center, by optimizing the roof angle, which is set to reduce the squish effect. The engine coolant flow and temperature are set to control the initial temperature before compression. The optical cylinder head is equipped with four cartridge heaters placed in the four corners and a type $K$ thermocouple is used to monitor the wall temperature. This system allows controlling the injector nozzle temperature. The NOSE combustion chamber has four gas connections: intake, air, vacuum and exhaust as illustrated in Figure 4. The intake connection is used to supply the vessel with working gases. Up to four gases (usually $\mathrm{N}_{2}, \mathrm{O}_{2}, \mathrm{NO}$, and $\mathrm{CO}_{2}$ ) can be supplied while controlling the amount of each gas. Mass Flow Controllers MFC (Brooks 5860S combined with 5850S) are used for this purpose. A liquid MFC is also installed on the same line, which allows injecting liquids in the chamber. At the end of the experiment, the gases are released through the exhaust connection. Then, the chamber is purged with air through a dedicated connection for at least $10 \mathrm{~s}$. Before starting a new experiment, the valves are closed and a vacuum pump is used to empty the chamber from all residual gases. The optical cylinder head is equipped with a piezoelectric pressure sensor (Kistler 7001). A National Instrument (NI) Compact RIO system is used to control the setup and to acquire the parameters of interest. Particularly, the in-cylinder pressure and temperature, the injector current and the encoder crank angle pulses are logged at $250 \mathrm{kHz}$. PRISME-NOSE is driven by a brushless (permanent magnet rotor) DC electric motor (Phase-Automation ${ }^{(}$U31340). The torque and engine speed are controlled with a dedicated electric driver (Phase-Automation ${ }^{\circledR}$ axM300-400) through the LabVIEW interface of the NOSE setup. First, a reverse mode is activated and the piston is moved from 180 CAD before TDC to 280 CAD before TDC. The system is then switched to velocity feedback mode based on a closed loop control. The high accuracy engine speed measured with the encoder is used to impose an optimized piston velocity profile (rapid compression $<40 \mathrm{~ms}$ and steady state at TDC $10 \mathrm{~ms}$ ). This method reduced the piston static friction and smoothed the piston motion. It also provides a satisfying repeatability of the piston velocity profiles. A comparison of the target and measured piston velocity is presented in Figure 5 demonstrating the effectiveness of the closed loop feedback control-mode. To reach the ECN spray A target conditions, the PRISME-NOSE is operated with a coolant temperature set at $356 \mathrm{~K}$ and an initial pressure of 1.8 bar (for inert experiments with $\mathrm{N}_{2}$ ). The optical cylinder head is heated up to reach $363 \mathrm{~K}$ in the injector nozzle region. Figure $6 \mathrm{a}$ illustrates the pressure, temperature, and density profiles obtained with these initial conditions. Figure 6b demonstrates the good repeatability of experiments at the SOI. More details about the NOSE can be found in [26, 27]. The time-resolved gas temperature is measured with thin wires $(12.7 \mu \mathrm{m})$ type $\mathrm{K}$ thermocouples and using an AD595CQ amplifier coupled to NI Analog Input module. Further details about the measurement technique are reported later in Section 4.2.5.

\subsection{Comparison}

The main features of the experimental facilities together with the settings for spray A experiments are compared in Table 1. Unlike CVP, PPRIME, and PRISME RCM reach the spray A target conditions through volumetric compression without the need for a pre-burn event. Therefore, the gas composition is relatively simpler in these devices. In PPRIME RCM, the lowest available $\mathrm{CR}$ is used to maximize the volume at the SOI $\left(131 \mathrm{~cm}^{3}\right)$. A controlled amount of Argon is added to $\mathrm{N}_{2}$ and $\mathrm{O}_{2}$ mixture to adjust the gas density and the heat capacity ratio, which enable reaching the target conditions. In PRISME NOSE, the compression ratio has been adapted to reach these conditions by using only the target ratio of $\mathrm{O}_{2}$ and $\mathrm{N}_{2}$. For reference, the heat capacity $C_{\mathrm{p}}$ at spray A conditions is reported 


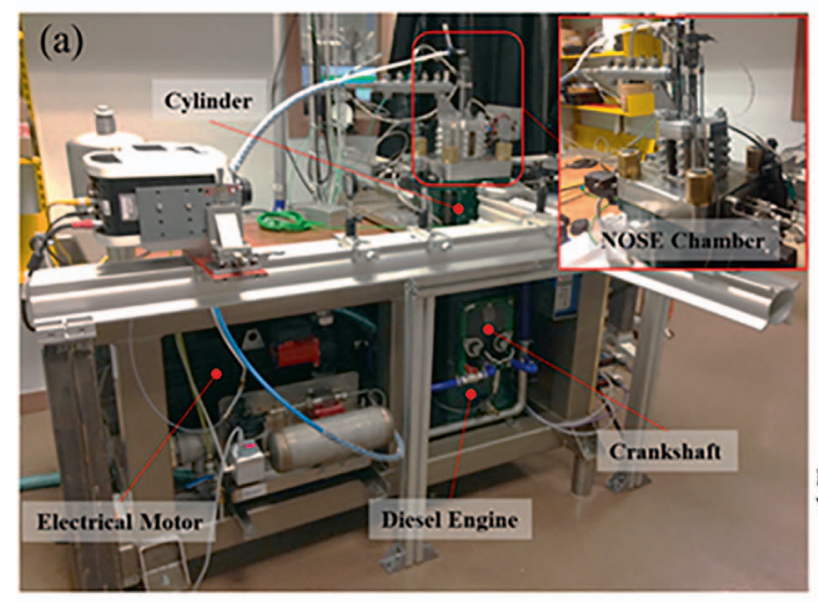

(c)

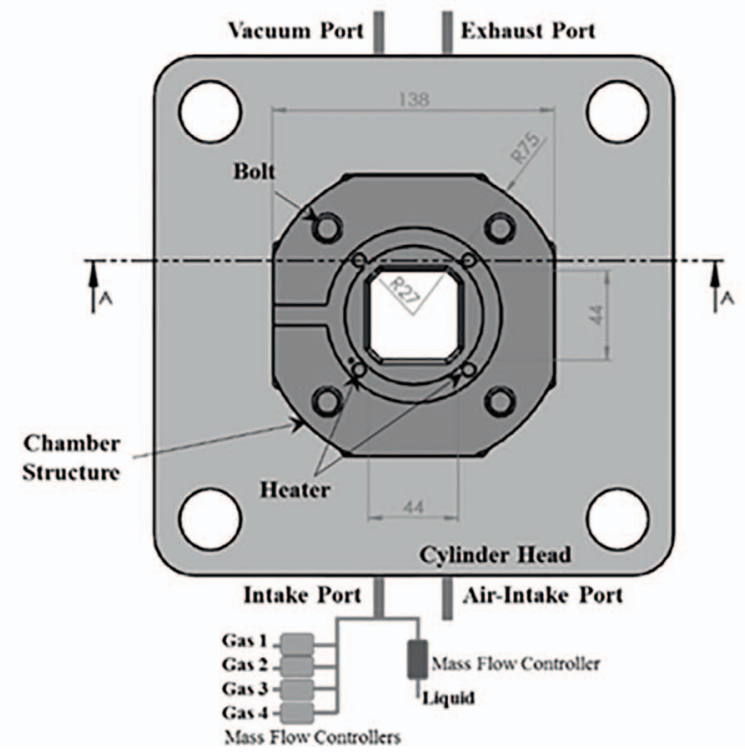

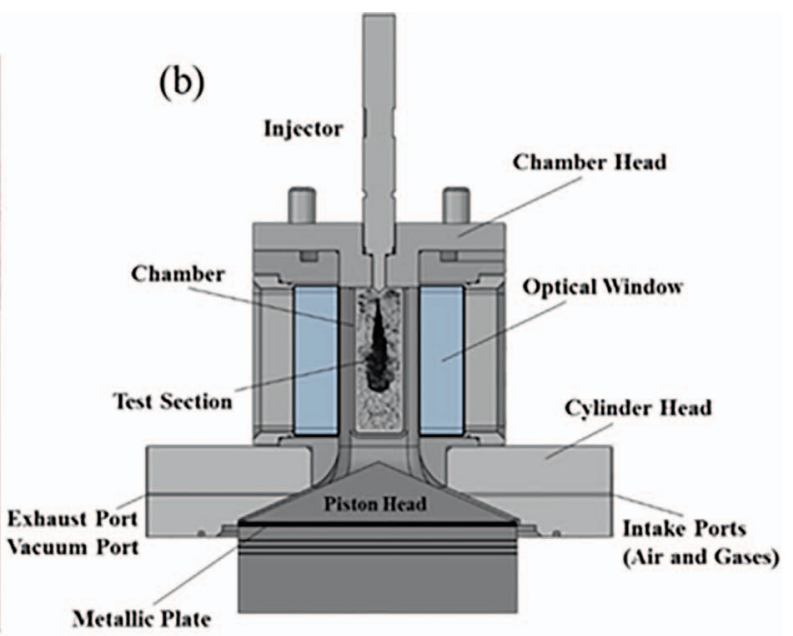

(d)

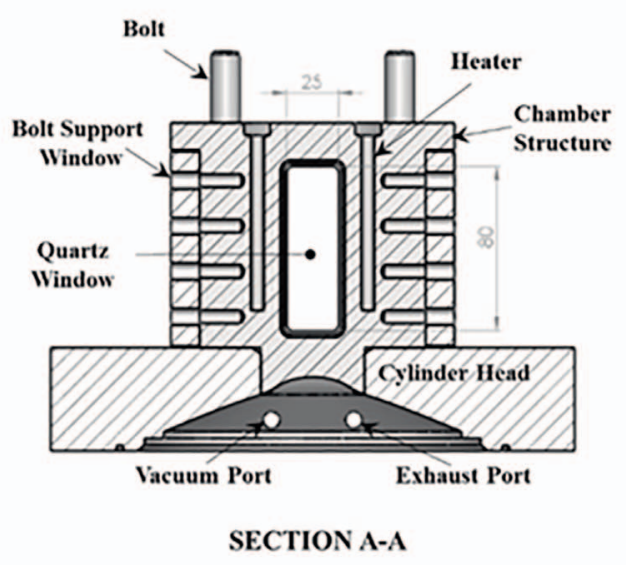

Fig. 4. The NOSE chamber: (a) the overview of real image, (b) the cross-section view in middle plane of chamber, (c) the top-view without chamber head, and (d) the cross-section view A-A without chamber head.

in Table 1, since this parameter has a primary role in the resulting temperature of the fuel-gas mixture and therefore it might have a non-negligible impact on the spray liquid length, ignition delay and lift off length. Similarly to PPRIME RCM, the volume of PRISME NOSE chamber at the time of injection $\left(240 \mathrm{~cm}^{3}\right)$ is significantly smaller than the one used in IFPEN CVP. The RCM devices have an order of magnitude smaller volume and their wall/body temperatures are $100 \mathrm{~K}$ lower compared to IFPEN, while the injector nozzles are protruding similarly.

In the early ECN studies [2,3], the spray experiments are always performed after a proper characterization of the boundary conditions. This step, often referred to as the "standardization", assures the accuracy of boundary conditions by: (i) providing a detailed list of conditions, which are not often considered in other studies (e.g., fuel temperature, gas velocities, etc.), (ii) sharing and discussing the characterization methodologies employed, together with the related uncertainties. In this work, the attention is focused on the characterization of three main boundary conditions:

- The gas velocity (this will be detailed in Sect. 3).

- The injector nozzle temperature (this will be detailed in Sect. 4.1).

- The gas temperature (this will be detailed in Sect. 4.2).

In the following, the results related to these characterizations will be presented and discussed. 


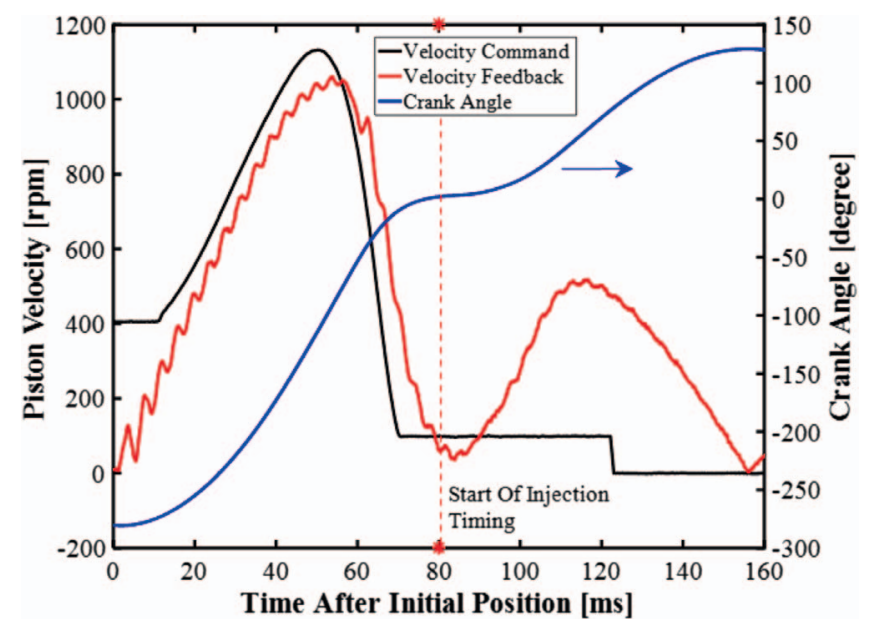

Fig. 5. NOSE operation: comparison of the feedback and command velocities as a function of time referenced to the initial position (280 CAD before TDC).

\section{Characterization of the gas velocity}

\subsection{PIV optical setup}

\subsubsection{IFPEN}

The PIV setup used in IFPEN is detailed in [28], where inert experiments were performed. A $10 \mathrm{kHz}$ dual cavity YLF laser was used to illuminate the seeded combustion chamber. A Photron SA1 CMOS camera equipped with a Nikkor $50 \mathrm{~mm} \mathrm{f} / 1.2$ lens was used to acquire the images at $20 \mathrm{kHz}$. The laser pulses had a $2 \mu$ s time delay, thus this time constant was used to calculate high velocity levels. Lower velocities were calculated using the $100 \mu$ s time step. The ROI was centered on the spray axis and has $56 \mathrm{~mm}$ width and $74 \mathrm{~mm}$ long (image resolution $8 \mathrm{~mm} /$ pixel). A sketch of the layout is presented in Figure 7.

\subsubsection{PPRIME}

In PPRIME, high-speed 2D PIV technique was performed to study the flow characteristics of the RCM at test conditions similar to those set for spray A experiments. A Mesa PIV Nd-Yag laser has been used to generate laser pulses at $10 \mathrm{kHz}$. The laser sheet was placed in the RCM center plane (coplanar to spray axis) and the chamber was seeded with Silicone oil droplets. A schematic of the PIV setup is presented in Figure 8 (more details are reported in [24]). The RCM settings are summarized in Table 2. The CR and the target density are similar to those used for spray A experiments (see Tab. 1). However, a lower target compression temperature is used to avoid the evaporation of the seeded oil droplets. This has a minor influence on the internal aerodynamics of the RCM. The characterization of the flow is focused on the injection period $\left(t_{\mathrm{inj}} \pm 10 \mathrm{~ms}\right)$. The velocity vectors are calculated with a time series pyramid sum of correlation algorithm [29] and using a decreasing window size of $128 \times 128-32 \times 32$ with $50 \%$ overlap (vector density 1.28 per $\mathrm{mm}$ ). The turbulence level was estimated based on a time averaging of 198 velocity fields and following the equations described in the next Section 3.2.

\subsubsection{PRISME}

In PRISME, similar high-speed PIV measurements were performed using a dual Hawk-HP Nd-Yag laser $(9.4 \mathrm{~mJ} /$ pulse, $532 \mathrm{~nm}$ at $2.5 \mathrm{kHz})$ and a Phantom CMOS camera. The NOSE chamber was also seeded with Silicon oil droplets and the laser sheet was placed in the center plane (an illustration is presented in Fig. 9). The velocity vectors are calculated using again a time series pyramid sum of correlation algorithm but using a decreasing window size of $64 \times 64-16 \times 16$ with $50 \%$ overlap.

\subsection{Velocity and turbulence at spray A conditions}

In PPRIME RCM and PRISME NOSE, the 2D PIV measurements were used to estimate the turbulence levels at the SOI. The calculations are based on time averaging in the range SOI $\pm 10 \mathrm{~ms}$ (using 198 velocity fields in PPRIME and 50 in PRISME). In IFPEN CVP, the 2D PIV measurements were more focused on the aerodynamics of the spray [28]. Only a limited number of flow fields are available without injection. Thus, the turbulence was estimated based on the ensemble averaging and using 73 velocity fields measured at the SOI.

The following equations are used for the calculation of the average velocity, the RMS and the turbulent kinetic energy TKE:

$$
\begin{gathered}
\bar{V}(x, y)=\frac{1}{N} \sum_{t=1}^{N} V(x, y, t), \\
\sigma(x, y)=\sqrt{\frac{1}{N-1} \sum_{t=1}^{N}(V(x, y, t)-\bar{V}(x, y))^{2}}, \\
\mathrm{TKE}=\frac{1}{2}\left(\sigma(x)^{2}+\sigma(y)^{2}+\left(\frac{\sigma(x)+\sigma(y)}{2}\right)^{2}\right) .
\end{gathered}
$$

The PIV results from PPRIME RCM, PRISME NOSE, and IFPEN CVP are presented in Figures 10-14 and summarized in Table 3, where spatially averaged data are compared to results reported in [30].

The data from all ECN facilities reported in Table 3 show that they comply with the spray A ambient gas near-quiescent condition. The standard condition implies that the maximum and average velocity at the SOI is lower than $1 \mathrm{~m} / \mathrm{s}$. However, different levels of velocities and turbulence are observed: the values in PPRIME RCM and Caterpillar CPF are an order of magnitude higher than in Sandia and IFPEN CVP. It is worth reminding that the turbulence level is dependent on the fan speed in CVP vessels. Higher fan speed would generate more temperature homogeneity but too high turbulence. As it was highlighted in [13], small differences in the turbulence level and the nozzle diameter between different ECN facilities are expected to cause a vapor distribution significantly different. 

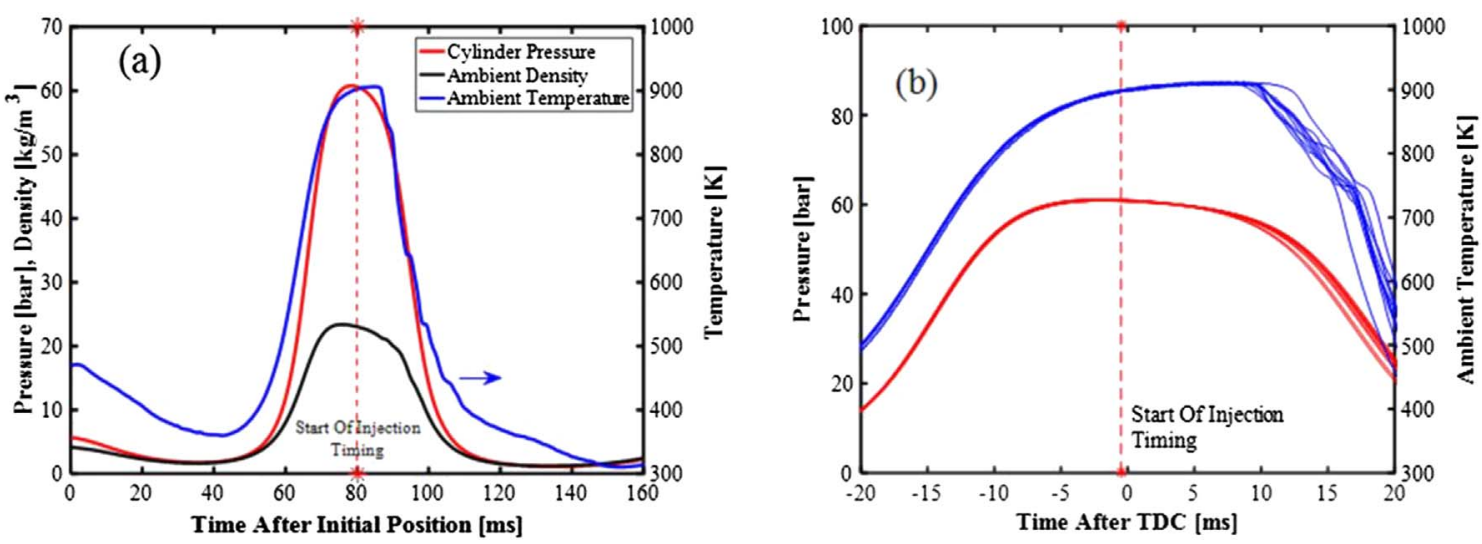

Fig. 6. Thermodynamic condition of NOSE operation: (a) an example of pressure, temperature and density temporal evolution, (b) pressure and temperature evolutions from $-20 \mathrm{~ms}$ to $20 \mathrm{~ms}$ after TDC for 10 repeated tests.
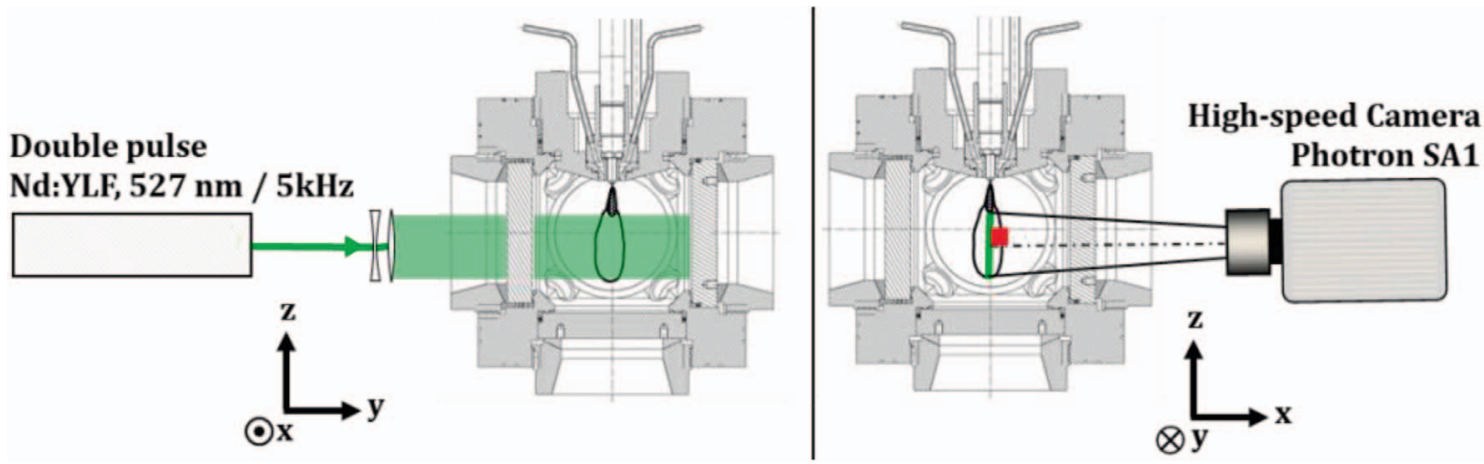

Fig. 7. Schematic of the PIV setup in IFPEN.

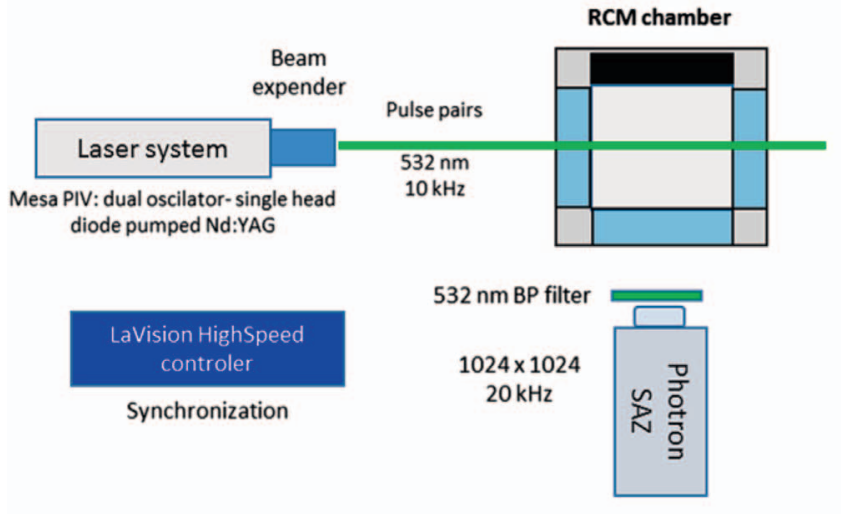

(a)

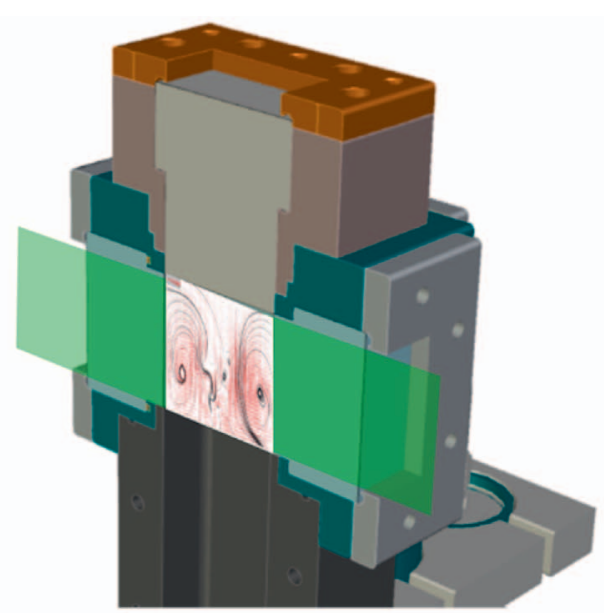

(b)

Fig. 8. Schematic of the PIV setup in PPRIME.

Thus, the early stages of the fuel-air mixing might be affected and lead to different ignition behaviors. This will be further investigated in [20], where spray behavior in current facilities will be compared. Although all facilities comply with the near quiescent condition, the estimated TKE is significantly different from one vessel to another. This also encourages considering a more realistic velocity and turbulence level when simulating the spray A. 
Table 2. RCM test conditions for PIV experiments.

\begin{tabular}{lc}
\hline Compression ratio CR & $9\left(\right.$ volume at $\left.\mathrm{TDC}^{2}=131 \mathrm{~cm}^{3}\right)$ \\
Wall temperature & $291 \mathrm{~K}$ \\
Gas composition & $\mathrm{CO}_{2} / \mathrm{N}_{2} / \mathrm{Ar} 4.75 / 52.53 / 42.72 \% \mathrm{~mol}$ \\
Average density & $23.5 \mathrm{~kg} / \mathrm{m}^{3}$ \\
Pressure at TDC & $51.6 \mathrm{bar}$ \\
Temperature at TDC & $T_{\mathrm{c}}=767 \mathrm{~K}$ \\
\hline
\end{tabular}

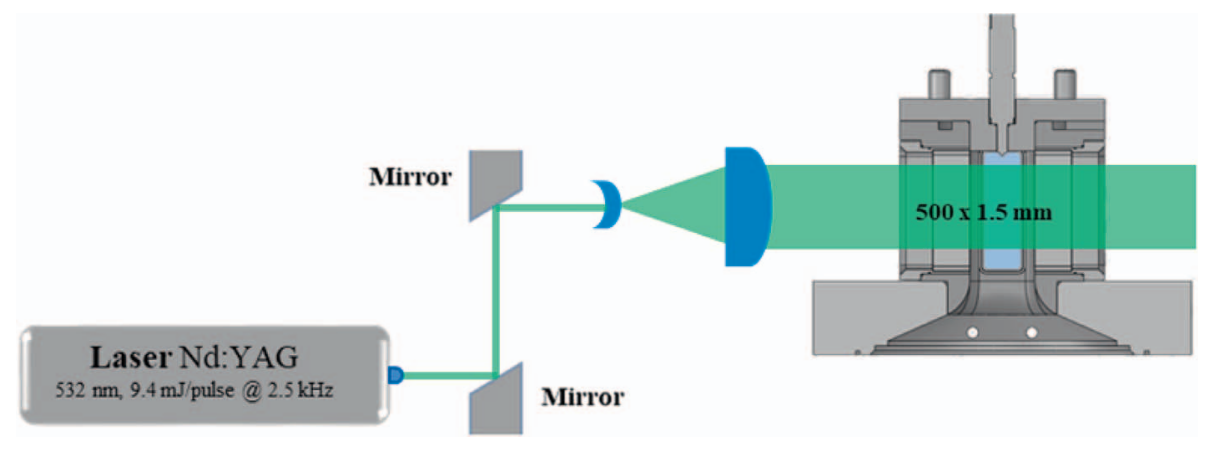

Fig. 9. Schematic of PIV setup in PRISME.
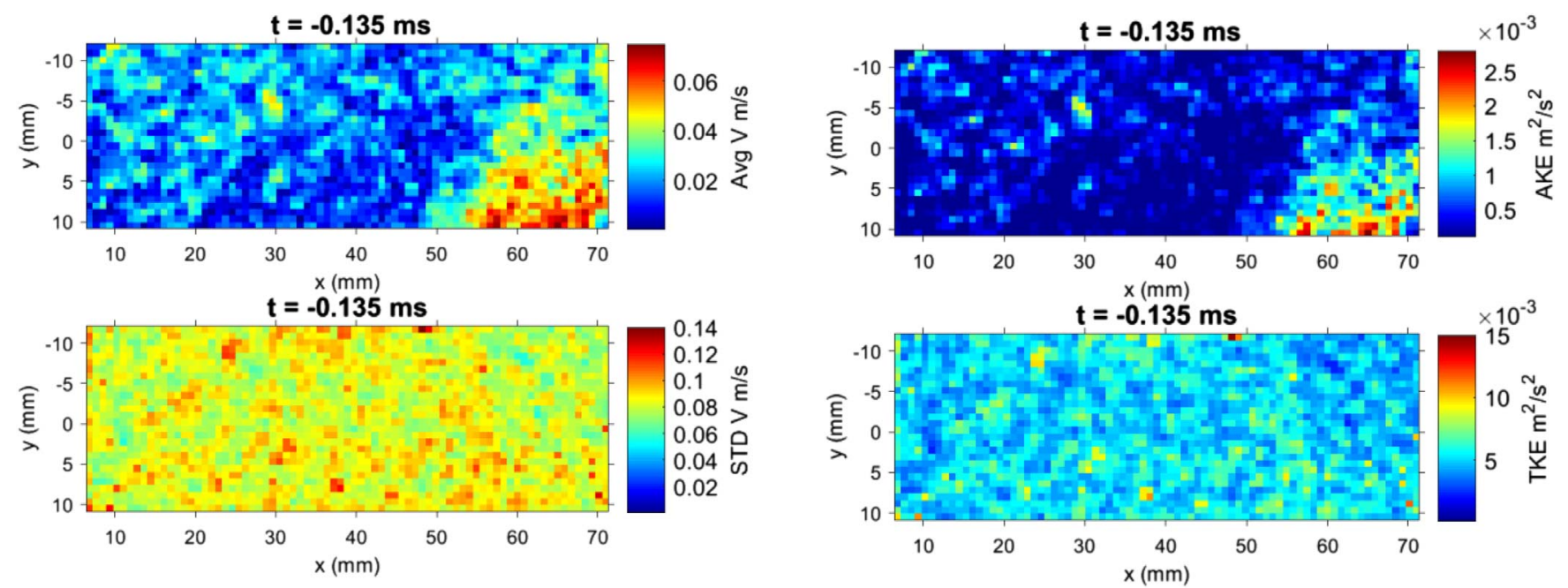

Fig. 10. Average and standard deviation of velocity magnitude at time of injection (IFPEN CVP using ensemble average).

\section{Characterization of temperature boundary conditions}

\subsection{Injector nozzle temperature}

The injector nozzle temperature is an important parameter for spray characterization. It is considered highly representative of fuel temperature, which has a first order influence on spray evaporation and auto-ignition [9]. At spray A reference conditions, it is estimated that all the injected fuel, for injections up to $4 \mathrm{~ms}$ long, is originally contained in a distance lower than $4 \mathrm{~mm}$ from the nozzle

Fig. 11. Average and turbulent kinetic energy at time of injection (IFPEN CVP using ensemble average).

sac $[3,9]$. Therefore, considering the long time between two consecutive injections ( $>60 \mathrm{~s}$ ) it can be considered that the fuel and the injector nozzle reach the same temperature. In current study, the injector nozzle temperature is measured with a dummy injector instrumented with a type $\mathrm{K}$ thermocouple. The same device was used in previous ECN characterizations $[2,3,9]$. At IFPEN, the CVP walls are heated up to $\sim 473 \mathrm{~K}$ and thus, the injector is water cooled down to the reference $363 \mathrm{~K}$. In PPRIME RCM and PRISME NOSE, the walls are heated respectively to $363 \mathrm{~K}$ and $373 \mathrm{~K}$. This ensures that the injector nozzle temperature is on the target standard value. In Figure 15, 


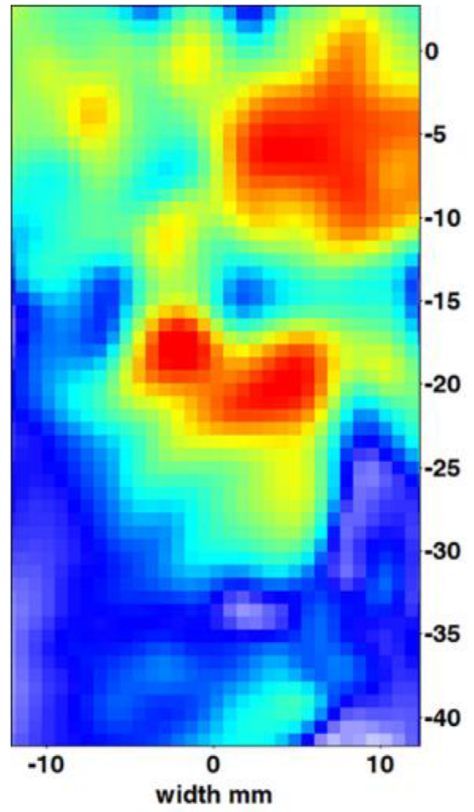

(a)
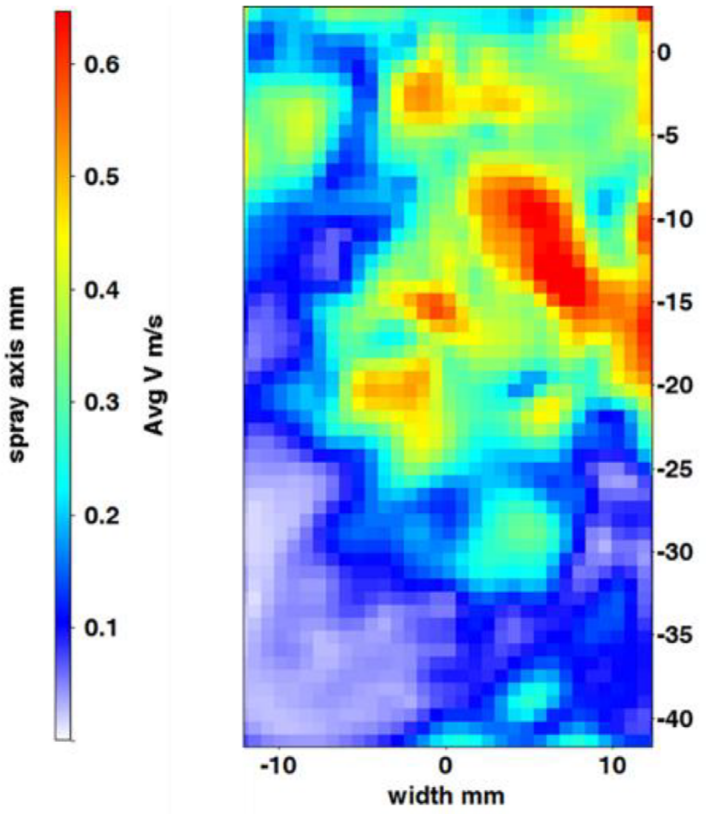

(b)

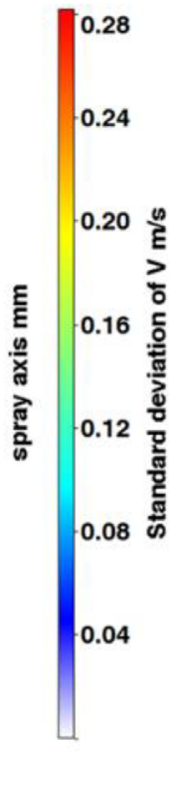

Fig. 12. (a) Average and (b) standard deviation of velocity magnitude at time of injection $\pm 10 \mathrm{~ms}(P P R I M E)$.

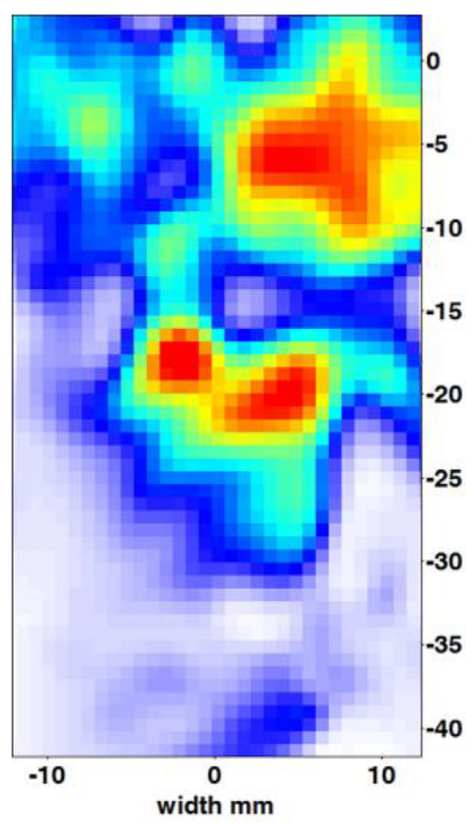

(a)
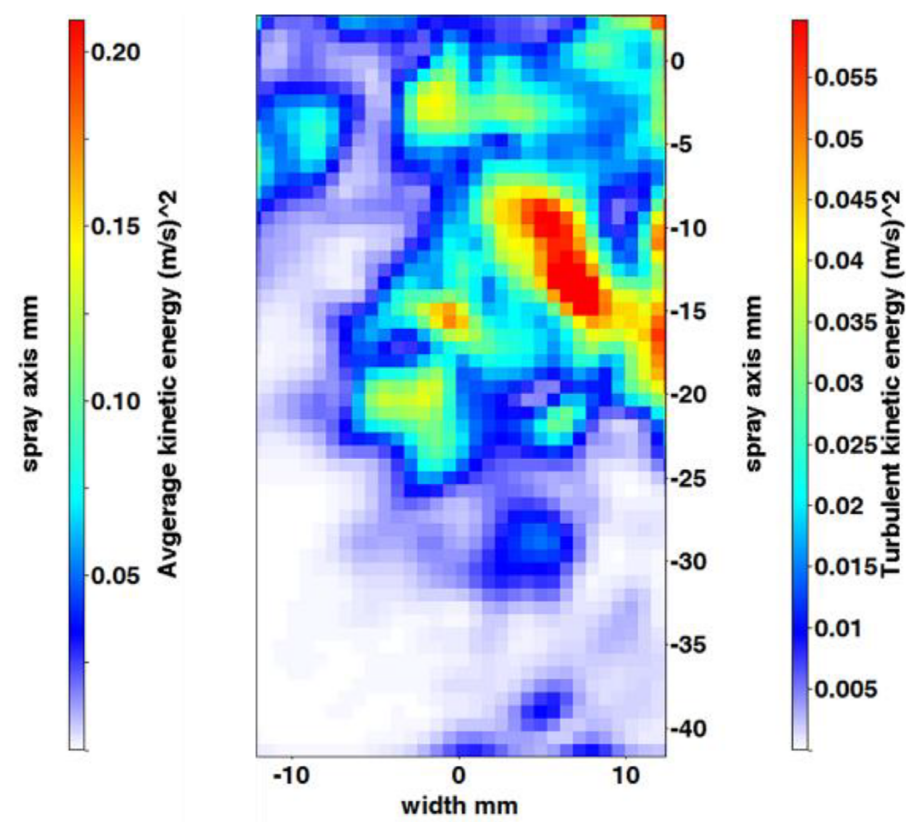

(b)

Fig. 13. (a) Average and (b) turbulent kinetic energy at time of injection $\pm 10 \mathrm{~ms}(P P R I M E)$.

the average nozzle temperatures measured with the dummy injector during a spray A experiment in IFPEN CVP and PPRIME RCM are compared. At the start of experiment, the temperature is well set on the target value. However, the pre-burn event in the CVP and the rapid compression of the RCM induce an increase of the nozzle temperature. At the instant of injection, the nozzle temperature on the
CVP increases, up to $10 \mathrm{~K}$ higher than at the start of experiment. The increase is less pronounced on the RCM (approximately $1 \mathrm{~K}$ ). Considering also the measurement performed in [2], it is reasonable to expect that the short time scale of the pre-combustion event does not affect significantly the fuel and nozzle temperature $(<20 \mathrm{~K})$. However, despite the small fuel volume interested by the 

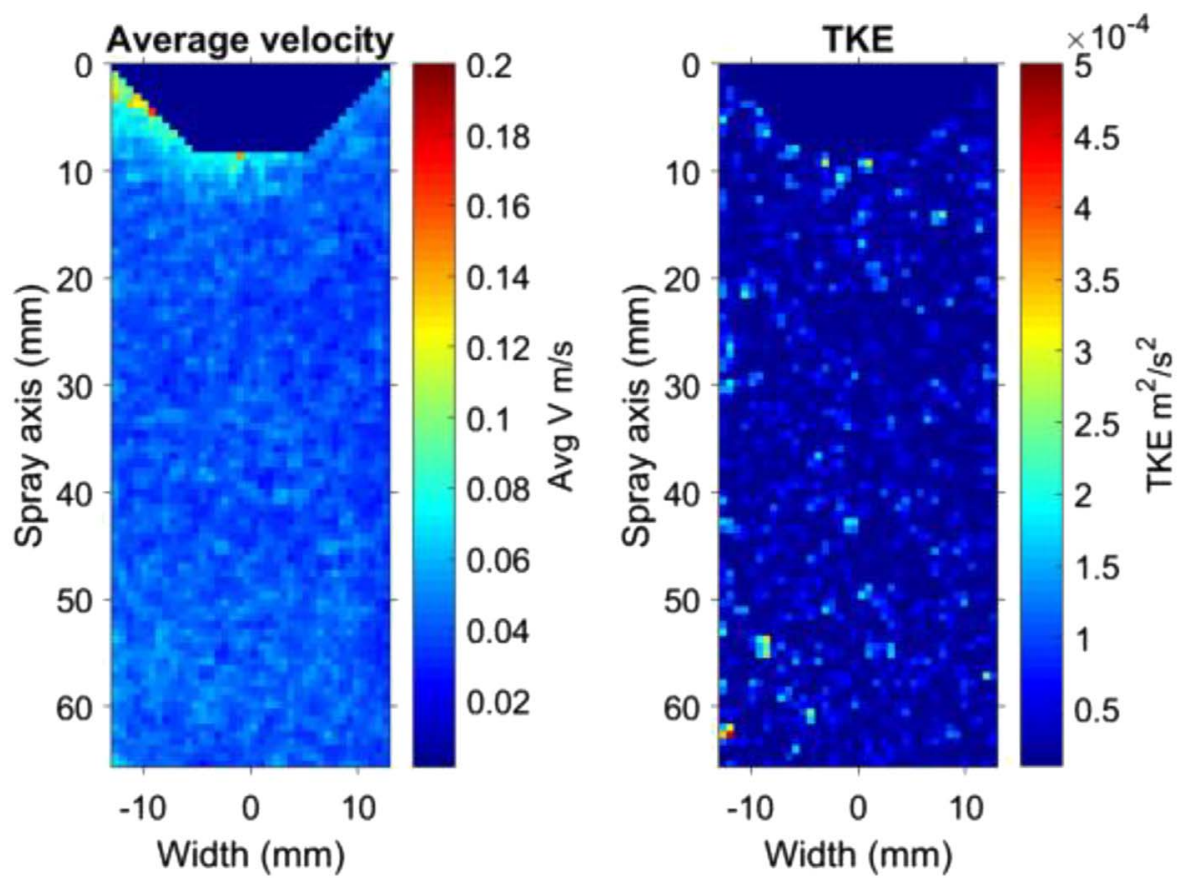

Fig. 14. (a) Average velocity magnitude field and (b) turbulent kinetic energy field at SOI (PRISME).

Table 3. Comparison of turbulence characteristics: Sandia CVP and Caterpillar CPV reported in [17, 30].

\begin{tabular}{lccccc}
\hline Institution vessel & Caterpillar CPF & Sandia CVP* & IFPEN CVP & PPRIME RCM & PRISME NOSE (RCM) \\
\hline AVG velocity & $0.12 \mathrm{~m} / \mathrm{s}$ & $0.03 \mathrm{~m} / \mathrm{s}$ & $0.024 \mathrm{~m} / \mathrm{s}$ & $0.282 \mathrm{~m} / \mathrm{s}$ & $0.043 \mathrm{~m} / \mathrm{s}$ \\
TKE & $0.008 \mathrm{~m}^{2} / \mathrm{s}^{2}$ & $0.0005 \mathrm{~m}^{2} / \mathrm{s}^{2}$ & $0.0062 \mathrm{~m}^{2} / \mathrm{s}^{2}$ & $0.0125 \mathrm{~m}^{2} / \mathrm{s}^{2}$ & $0.00003 \mathrm{~m}^{2} / \mathrm{s}^{2}$
\end{tabular}

${ }^{*}$ Fan speed $=1000 \mathrm{rpm}$.

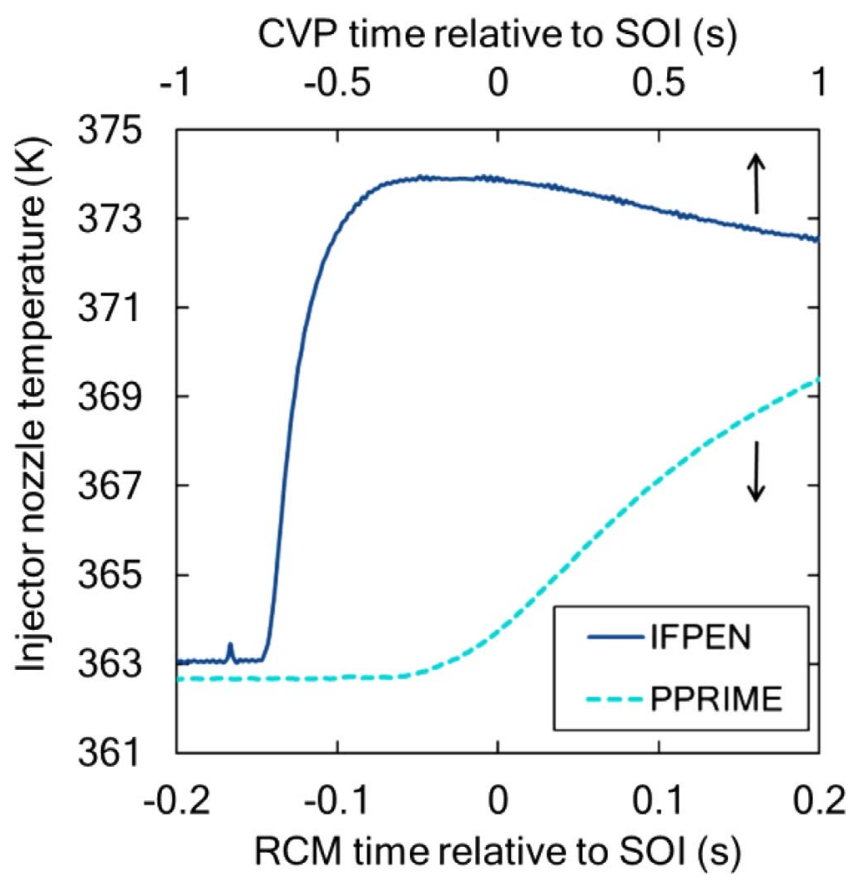

Fig. 15. Comparison of the injector nozzle temperature in IFPEN CVP and PPRIME RCM. The time is referenced to the SOI. injection, we cannot exclude some fuel temperature gradient during the injection. According to what is reported in [9], $10 \mathrm{~K}$ difference in the fuel temperature could cause a difference in liquid length of $\sim 0.3 \mathrm{~mm}$ and $0.1 \mathrm{~mm}$ in lift-off length. The effects of boundary conditions on the spray characteristics will be further discussed in [20].

\subsection{Gas temperature measurements}

\subsubsection{General methodology}

Many optical diagnostic techniques could be used for local temperature measurements at ECN test conditions. A brief review of these methods is presented in Table 4 [31]. In RCMs and CPFs, where oxygen free gases can be used, Laser Induced Fluorescence (LIF) with different tracers (acetone [32], toluene [33], or anisole [34]) could be considered. LIF methods can provide spatially resolved information, which would facilitate the characterization of the combustion vessels used for ECN spray studies. However, it could have limitation at relatively high temperature, as the tracer pyrolysis should be considered when calculating the temperature from the fluorescence signal. In addition, thermal quenching significantly reduces florescence signal at high temperatures (e.g., $900 \mathrm{~K}$ ), increasing measurement uncertainties. Laser Rayleigh scattering [35-37] is 
Table 4. Summary of optical diagnostic techniques that could be used in ECN spray vessels [31].

\begin{tabular}{|c|c|c|c|c|c|}
\hline Method & $\begin{array}{c}\text { Temperature } \\
\text { range } \\
\min / \max \\
\left({ }^{\circ} \mathrm{C}\right)\end{array}$ & $\begin{array}{c}\text { Response/ } \\
\text { transient } \\
\text { capability }\end{array}$ & Accuracy & $\begin{array}{l}\text { Commercially } \\
\text { available/ } \\
\text { relative cost }\end{array}$ & $\begin{array}{c}\text { General } \\
\text { description }\end{array}$ \\
\hline Rayleigh scattering & $20 / 2500$ & Very fast/yes [43] & $1 \%$ & No/very high & $\begin{array}{c}\text { Non-intrusive. } \\
\text { Can be susceptible to } \\
\text { background interference. }\end{array}$ \\
\hline Raman scattering & $20 / 2227$ & Very fast/yes [44] & $\begin{array}{c}7 \% \\
2 \%[45]\end{array}$ & No/very high & Non-intrusive. \\
\hline $\begin{array}{l}\text { Coherent Anti-Stokes } \\
\text { Raman Scattering } \\
\text { (CARS) }\end{array}$ & $20 / 2000$ & Fast/NA & $5 \%$ & Yes/very high & Non-intrusive. \\
\hline $\begin{array}{l}\text { Laser Induced } \\
\text { Fluorescence (LIF) }\end{array}$ & $0 / 2700$ & Very fast/yes & $10 \%$ & No/very high & $\begin{array}{l}\text { Non-intrusive. Can be } \\
\text { limited by quenching } \\
\text { phenomena. }\end{array}$ \\
\hline $\begin{array}{l}\text { Laser absorption } \\
\text { spectroscopy }\end{array}$ & $20 / 2500$ & Very fast/yes [40] & $\begin{array}{c}15 \% \\
5 \%[40]\end{array}$ & Yes/low & $\begin{array}{l}\text { Non-intrusive. Line of } \\
\text { sight averaging (limited } \\
\text { special resolution). }\end{array}$ \\
\hline $\begin{array}{l}\text { Thermographic } \\
\text { phosphors }\end{array}$ & $-250 / 2000$ & Very fast/yes & $0.1-5 \%$ & Yes/high & Semi-intrusive. \\
\hline $\begin{array}{l}\text { Interferometry } \\
\text { Laser Induced Grating } \\
\text { Spectroscopy (LIGS) }\end{array}$ & $0 / 2300$ & Fast/yes & $1.4-5 \%[41,42]$ & No/high & Non-intrusive. \\
\hline
\end{tabular}

commonly used in gas phase thermometry. However, this technique can be limited by the background interference, which causes a too low signal to noise ratio. Laser absorption thermometry $[38,39]$ is relatively easy to install and can be time-resolved [40]. The measurement is performed in the line of sight, which makes the method not suitable for the assessment of temperature gradients. Recently, Laser Induced Grating Spectroscopy (LIGS) was successfully performed to measure temperature at ECN like conditions [41, 42]. This method measures local temperature with a relatively good accuracy and can be time resolved. Thinwire thermocouples are easier to install and can perform similar measurements. However, they are more intrusive compared to LIGS.

\subsubsection{Thin-wire thermocouple thermometry}

Thermocouple thermometry is often used for the study of temperature fluctuations in turbulent flows [46, 47]. The proper design of these sensors and the use of extremely thin wires enable fast response with a relatively good accuracy. The study of their time response is usually performed based on the theory of frequency response [48-51]. To have a fast response thermocouple, the sensor should be bare-bead with junction on wires as small as possible. It is recommended to ground isolate the junction to reduce the noise potentially caused by Electro-Magnetic Interference (EMI). The welding of the junction on extremely small wires can be achieved using capacitive discharge technique after an optimization of the discharge parameters. Recommended settings for this method are described in [52]. Thermocouples measure the temperature of the junction based on the Seebeck effect. To measure gas temperature, the heat exchange around the sensor must be modeled [47, 53]. Assuming energy conservation on the junction, the gas temperature $T_{\mathrm{g}}$ and the junction temperature $T_{\mathrm{j}}$ can be correlated. The main heat exchanges on the junction are through: (i) convection between gas and junction, (ii) radiation between walls and junction, (iii) conduction between junction and the prongs. The heat transfer by dissipation is often neglected at relatively low flow velocities. The radiation between the junction and the gas is usually negligible compared to the radiation to the wall. Catalytic reactions can occur between the sensor wires and the gas. In such cases, the heat transfer would depend on the main chemical reactions involved in this phenomenon. Catalytic reactions make the sensor more intrusive especially in unstable gas environments. This was the case when using type $\mathrm{R}$ thermocouples in some ECN CVP vessels [2]. The sensor wires can be coated to avoid their catalytic effect, as proposed in $[47,54,55]$. However, this would modify the convective and radiative heat transfers. Based on the previous assumptions, the gas temperature can be modeled as follows:

$$
T_{\mathrm{g}}=T_{\mathrm{j}}+\left(\tau_{\mathrm{h}}+\tau_{\mathrm{c}}\right) \frac{\mathrm{d} T_{\mathrm{j}}}{\mathrm{d} t}+\frac{\sigma \varepsilon}{h}\left(T_{1}^{4}-T_{\mathrm{s}}^{4}\right),
$$

where: $\sigma$ is the Stefan-Boltzmann constant, $\varepsilon$ is the temperature dependent emissivity (typical value for thermocouple wire can be found in [56]), $h$ is the convection 

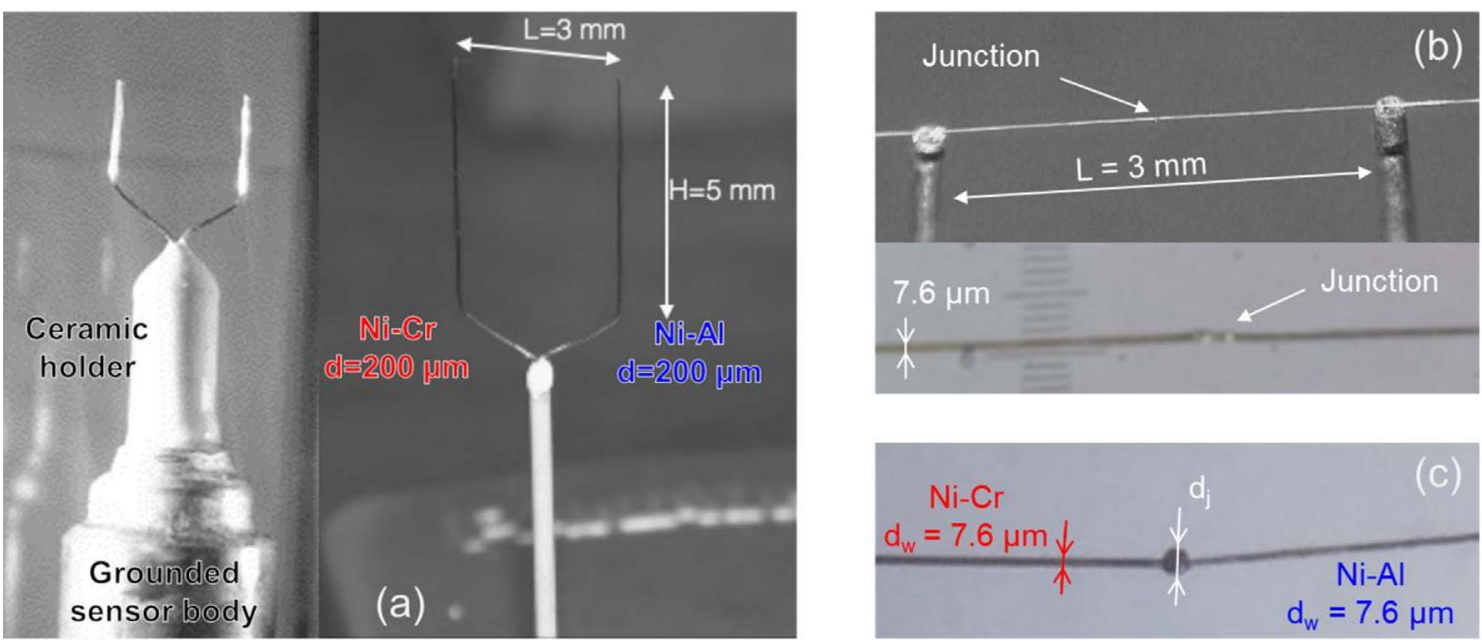

Fig. 16. Schematic of the $7.6 \mu \mathrm{m}$ thermocouple sensor (PPRIME institute): (a) sensor prongs mounting, (b) zoom on the thermocouple junction welded successfully, (c) zoom on junction having a spherical shape.

heat-transfer coefficient, $T_{\mathrm{s}}$ is the temperature of wall surfaces surrounding the junction, and $\tau_{\mathrm{h}}$ and $\tau_{\mathrm{c}}$ are respectively the time constant of the convective heat-transfer contribution and the time constant of the conduction heat-transfer contribution.

In the early studies on cold wires thermometry [57, 58], a cooled length from conduction $l_{\mathrm{c}}$ has been defined to describe the characteristic length of the conduction heat transfer in these applications. Applying this theory to thin-wire thermocouples would imply a design condition that will reduce substantially the errors from the conduction losses. It has been demonstrated in [47] that conduction losses from the junction to the prongs through thin-wires can be neglected if $L / l_{\mathrm{c}}>10$. Where $L$ is the length of the wires between the two prongs and $l_{\mathrm{c}}$ is defined as follows:

$$
l_{\mathrm{c}}=\frac{d_{\mathrm{w}}}{2} \sqrt{\frac{\lambda_{\mathrm{w}}}{\lambda_{\mathrm{g}} \mathrm{Nu}}}
$$

where $d_{\mathrm{w}}$ is the wire diameter, $\lambda_{\mathrm{w}}$ and $\lambda_{\mathrm{g}}$ are respectively the wire and the gas thermal conductivity, $\mathrm{Nu}$ is the Nusselt number. For typical sensors and gas flow applications, this condition is equivalent to $L / d_{\mathrm{w}} \geq 400$. With this design condition, the gas temperature can be calculated as:

$$
T_{\mathrm{g}}=T_{\mathrm{j}}+\tau_{\mathrm{h}} \frac{\mathrm{d} T_{\mathrm{j}}}{\mathrm{d} t}+\frac{\sigma \varepsilon}{h}\left(T_{\mathrm{j}}^{4}-T_{\mathrm{s}}^{4}\right)
$$

where $\tau_{\mathrm{h}}$ is:

$$
\tau_{\mathrm{h}}=\frac{\rho_{\mathrm{j}} C_{\mathrm{j}} d_{\mathrm{j}}}{4 h}
$$

$\rho_{\mathrm{j}}$ is the thermocouple junction density, $c_{\mathrm{j}}$ is the junction specific heat, $d_{\mathrm{j}}$ is the junction diameter and $h$ is the convective heat-transfer coefficient, which can be calculated from the Nusselt number:

$$
\mathrm{Nu}=\frac{h d_{\mathrm{j}}}{\lambda_{\mathrm{g}}} .
$$

Many Nusselt correlations can be found in the literature. Usually, the correlations depend on the flow configuration and the Reynolds (Re) and Prandtl (Pr) numbers. Collis and Williams [59] proposed for $0.02<\operatorname{Re}<44$ :

$$
\mathrm{Nu}=\left(0.24+0.51 \operatorname{Re}^{0.45}\right)\left(\frac{T_{\mathrm{f}}}{T_{\mathrm{g}}}\right)^{0.17},
$$

where $T_{\mathrm{f}}$ is the film temperature defined by Collis and Williams [60] as $\left(T_{\mathrm{g}}+T_{\mathrm{j}}\right) / 2$. Using the same definition of the reference temperature for the fluid physical properties, Kramers [61] proposed a generalized correlation:

$$
\mathrm{Nu}=2+1.3 \operatorname{Pr}^{0.15}+0.66 \operatorname{Pr}^{0.31} \operatorname{Re}^{0.5},
$$

and a specific one for the configurations where $0.01<\operatorname{Re}<10000$ and $0.71<\operatorname{Pr}<1000$ [61]:

$$
\mathrm{Nu}=0.42 \operatorname{Pr}^{0.2}+0.57 \operatorname{Pr}^{0.33} \operatorname{Re}^{0.5} \text {. }
$$

Churchill and Bernstein [62] proposed a generalized correlation for forced convection heat transfer across a cylinder, which was validated on a wide range of conditions $(\operatorname{Re} \operatorname{Pr}>0.2)$ :

$$
\mathrm{Nu}=0.3+\frac{0.62 \operatorname{Pr}^{1 / 3} \operatorname{Re}^{1 / 2}}{\left[1+(0.4 / \mathrm{Pr})^{2 / 3}\right]^{1 / 4}}\left[1+\left(\frac{\operatorname{Re}}{282000}\right)^{5 / 8}\right]^{4 / 5} .
$$

In the case of thin-wire thermocouples designed as described above, Re and Pr numbers are defined as follows:

$$
\mathrm{Re}=\frac{U d_{\mathrm{j}}}{v_{\mathrm{g}}},
$$



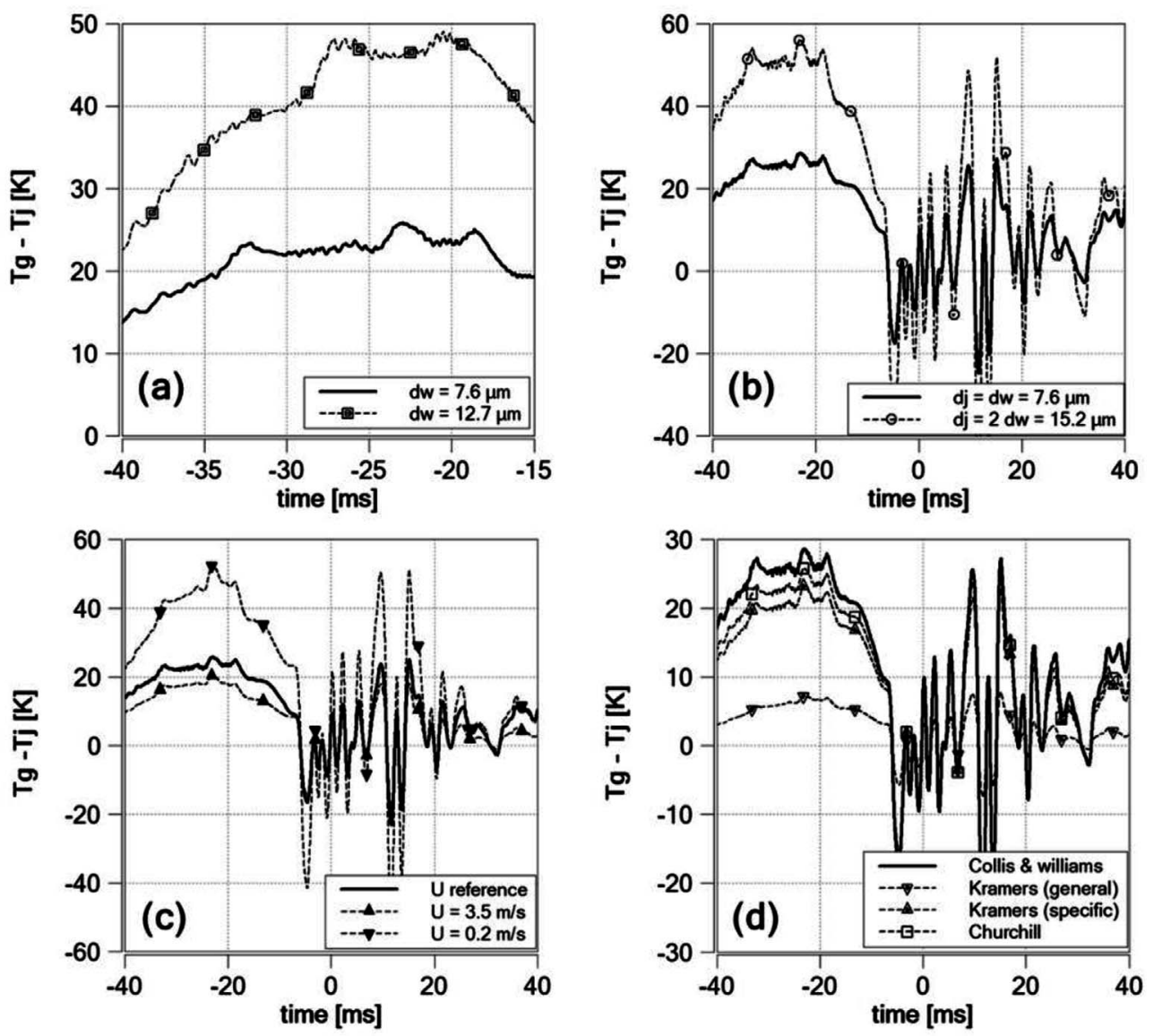

Fig. 17. Main parameters affecting the measured temperature correction: (a) effect of $d_{\mathrm{w}}$, (b) effect of $d_{\mathrm{j}} / d_{\mathrm{w}}$, (c) effect of the gas velocity $U\left(d_{\mathrm{w}}=7.6 \mu \mathrm{m}\right),(\mathrm{d})$ effect of the Nu correlation $\left(d_{\mathrm{w}}=7.6 \mu \mathrm{m}\right)$. PPRIME RCM test at spray A target conditions (time axis is referenced to the end of compression).

$$
\operatorname{Pr}=\frac{\mu_{\mathrm{g}} C_{\mathrm{p}}}{\lambda_{\mathrm{g}}},
$$

where $U$ is the gas velocity, $v_{\mathrm{g}}$ is the kinematic viscosity, $\mu_{\mathrm{g}}$ is the gas dynamic viscosity and $C_{\mathrm{p}}$ is the gas specific heat capacity. Thus, the calculation of the gas temperature from the measured junction temperature is highly affected by the wire diameter $d_{\mathrm{w}}$, the junction size $d_{\mathrm{j}} / d_{\mathrm{w}}$, the local gas velocity $U$ and the $\mathrm{Nu}$ correlation.

In PPRIME, the thermocouples used are bare-bead and ground isolated. The junction is welded on a $7.6 \mu \mathrm{m}$ type $\mathrm{K}$ wires, which are mounted in a strained position between similar wires of $200 \mu \mathrm{m}$ diameter. An illustration of these sensors is presented in Figure 16. The distance between the two prongs is approximately 400 times greater than the wire diameter. In most cases, the junction is perfectly welded and its size is as small as the wires, as demonstrated in Figure 16b. In few cases, the junction has a spherical shape and is slightly bigger than the wires, as illustrated in Figure 16c. A test run has been performed in PPRIME at spray A target conditions, using simultaneously two thermocouples with wires diameters of $7.6 \mu \mathrm{m}$ and $12.7 \mu \mathrm{m}$ and mounted in the center of the RCM chamber. The comparison of the corrected temperature is presented in Figure 17 to investigate the main parameters contributing in the measurement error. The effects of $d_{\mathrm{w}}, d_{\mathrm{j}}, U$, and $\mathrm{Nu}$ correlations are highlighted here. In default error calculation, the velocity considered is time-resolved and estimated from PIV measurements and the Churchill correlation for $\mathrm{Nu}$ (Eq. (12)) is used. The comparison of the correction $\left(T_{\mathrm{g}}-T_{\mathrm{j}}\right)$ in Figure 17a is focused on the compression step where it is demonstrated that the temperature is homogeneous in both thermocouples locations [23, 25]. The correction is approximately twice higher when using the $12.7 \mu \mathrm{m}$ thermocouple. In applications where temperature fluctuates significantly, it is expected to have higher corrections when using thicker wires. The use of smaller thermocouples substantially reduces the need for correction and improves the time response of the sensor. It is also important to consider the effective size of the thermocouple junction. For instance, this was the case for the welding presented in Figure 16c. In Figure 17b, it is demonstrated that an under-estimation of the junction size would result in an under-estimation of the correction and thus a systematic error on the estimation of the temperature. One of the difficulties of thermocouple thermometry is the proper estimation of the fluid velocity across the junction. In Figure $17 \mathrm{c}$, three estimations of the gas velocity have been 
Table 5. Summary of temperature measurement with thermocouples under spray A conditions $[2,3]$.

\begin{tabular}{|c|c|c|c|c|c|c|}
\hline \multirow[t]{2}{*}{ Institution } & \multirow[t]{2}{*}{ Facility } & \multirow{2}{*}{$\begin{array}{c}\text { Thermocouple } \\
\text { type }\end{array}$} & \multicolumn{4}{|c|}{ Error corrections } \\
\hline & & & Hypothesis & Convection $\mathrm{I}$ & Radiation & $\begin{array}{l}\text { Estimated } \\
\text { correction }\end{array}$ \\
\hline Sandia & CVP & $\begin{array}{l}\text { Bare bead } \\
\text { type-R }(50 \mu \mathrm{m}) \text { : } \\
\mathrm{Pt} / \mathrm{Pt}+13 \mathrm{Rh}\end{array}$ & $\begin{array}{c}\text { Conduction error neglected } \\
T_{\mathrm{g}}=T_{\mathrm{j}}+\tau \frac{\mathrm{d} T_{\mathrm{j}}}{\mathrm{d} t}+\frac{\sigma \varepsilon}{h}\left(T_{\mathrm{j}}^{4}-T_{\mathrm{s}}^{4}\right)\end{array}$ & Yes & Yes & $\begin{array}{c}4-10 \mathrm{~K} \\
(\text { at } 900 \mathrm{~K})\end{array}$ \\
\hline TUE & CVP & $\begin{array}{c}\text { Bare bead } \\
\text { type-R } \\
(50 \mu \mathrm{m}): \\
\mathrm{Pt} / \mathrm{Pt}+13 \mathrm{Rh}\end{array}$ & $\tau=\frac{\rho_{\mathrm{t}} C_{\mathrm{t}} d_{\mathrm{t}}}{4 h}$ & Yes & Yes & $\begin{array}{c}4-10 \mathrm{~K} \\
(\text { at } 900 \mathrm{~K})\end{array}$ \\
\hline IFPEN & CVP & $\begin{array}{l}\text { Bare bead } \\
\text { type-K } \\
(50 \mu \mathrm{m}): \\
\mathrm{Ni} / \mathrm{Cr}\end{array}$ & $h=\frac{0.56 \mathrm{~K} U^{0.45}}{d_{\mathrm{j}}^{0.55} v^{0.45}}$ & Yes & Yes & $\begin{array}{c}4-10 \mathrm{~K} \\
(\text { at } 900 \mathrm{~K})\end{array}$ \\
\hline Caterpillar & $\mathrm{CPF}$ & $\begin{array}{c}\text { Sheathed } \\
\text { type-K } \\
(1 \text { and } 3 \mathrm{~mm}) \text { : } \\
\mathrm{Ni} / \mathrm{Cr}\end{array}$ & $\begin{array}{l}\text { - Temperature is homogeneous in } \\
\text { the small volume where the different } \\
\text { thermocouples with different } \\
\text { diameters are placed. } \\
\text { - Temperature is averaged over } 10 \mathrm{~s} \\
\quad T_{\mathrm{g}}=T_{\mathrm{j}}+\frac{\sigma \varepsilon v^{0.45} d^{0.55}}{0.56 k U^{0.45}}\left(T_{\mathrm{j}}^{4}-T_{\mathrm{s}}^{4}\right)\end{array}$ & $\begin{array}{l}\text { No correction } \\
\text { (temperature } \\
\text { time } \\
\text { averaged) }\end{array}$ & Yes & - \\
\hline$C M T$ & $\mathrm{CPF}$ & $\begin{array}{l}\text { Sheathed } \\
\text { type-K : } \\
\mathrm{Ni} / \mathrm{Cr}\end{array}$ & $\begin{array}{l}\text { - Temperature is homogeneous in } \\
\text { the small volume where the different } \\
\text { thermocouples with different diameters } \\
\text { are placed. } \\
\text { - Temperature is averaged over } 20 \mathrm{~s} \\
T_{\mathrm{g}}=T_{\mathrm{j}}+k d^{0.55} \text {. }\end{array}$ & $\begin{array}{l}\text { No correction } \\
\text { (temperature } \\
\text { time } \\
\text { averaged) }\end{array}$ & Yes & - \\
\hline
\end{tabular}

used for the calculation of temperature correction for a $7.6 \mu \mathrm{m}$ thermocouple diameter: " $U$ reference" a time resolved estimation based on PIV measurements in the location of the sensor; " $U=3.5 \mathrm{~m} / \mathrm{s}$ " a constant velocity whose level is representative of the maximum velocity in the compression step; and " $U=0.2 \mathrm{~m} / \mathrm{s}$ " a constant velocity whose level is representative of average velocity in the late post-compression step. It is demonstrated that an over-estimation of the gas velocity would lead to an under-estimation of the error correction. Conversely, an under-estimation of the velocity would result in a substantial increase of the error correction and thus an overestimation of the temperature fluctuations. It is then very important to estimate properly the velocity across the sensor wires as this parameter highly influences the convective heat transfer coefficient $h$. The Nu correlation choice is also important for the estimation of this coefficient. The error corrections from the commonly used correlations in thermocouple thermometry are presented in Figure 17d. It is demonstrated that the use of the Kramers generalized correlation (Eq. (10)) would lead to the under-estimation of the temperature fluctuation in this case. All the other correlations have similar temperature correction. In configurations where the junction size is as small as the wires, it is more suitable to use the Churchill correlation (Eq. (12)).

\subsubsection{Previous gas temperature measurement in ECN facilities}

In most ECN studies, thin-wire thermocouples were used for the measurement of ambient gas temperature. Mainly, two types of thermocouples were used ( $\mathrm{R}$ and $\mathrm{K})$. Type $\mathrm{R}$ thermocouples are easily available and are able to measure high temperatures (up to $1873 \mathrm{~K}$ ), which is particularly needed in CVP vessels. Nevertheless, the catalytic effect of type $\mathrm{R}$ wires $(87 \% \mathrm{Pt} / 13 \% \mathrm{Rh}-\mathrm{Pt})$ have limited their use as uncontrolled pre-burn events may occur, particularly when the reactant gases are introduced sequentially in the CVP chamber [2]. Type $\mathrm{K}$ thermocouples, despite a lower maximum measured temperature (approximately $1520 \mathrm{~K}$ ), are widely used in many applications and were suitable for measuring gas temperature in RCM and CPF. Different methods for "temperature correction" have been used in the ECN community and many recommendations have been highlighted to improve the measurement accuracy $[2,3]$. Table 5 summarizes the different thermocouples and correction methods used in previous ECN studies. In CPF vessels, sheathed thermocouples were used since this type of facility provides steady thermodynamic conditions within the chamber. This configuration of the sensors is not suitable for measuring fast temperature fluctuation as the heat transfer by conduction has a relatively long time constant. Covering 


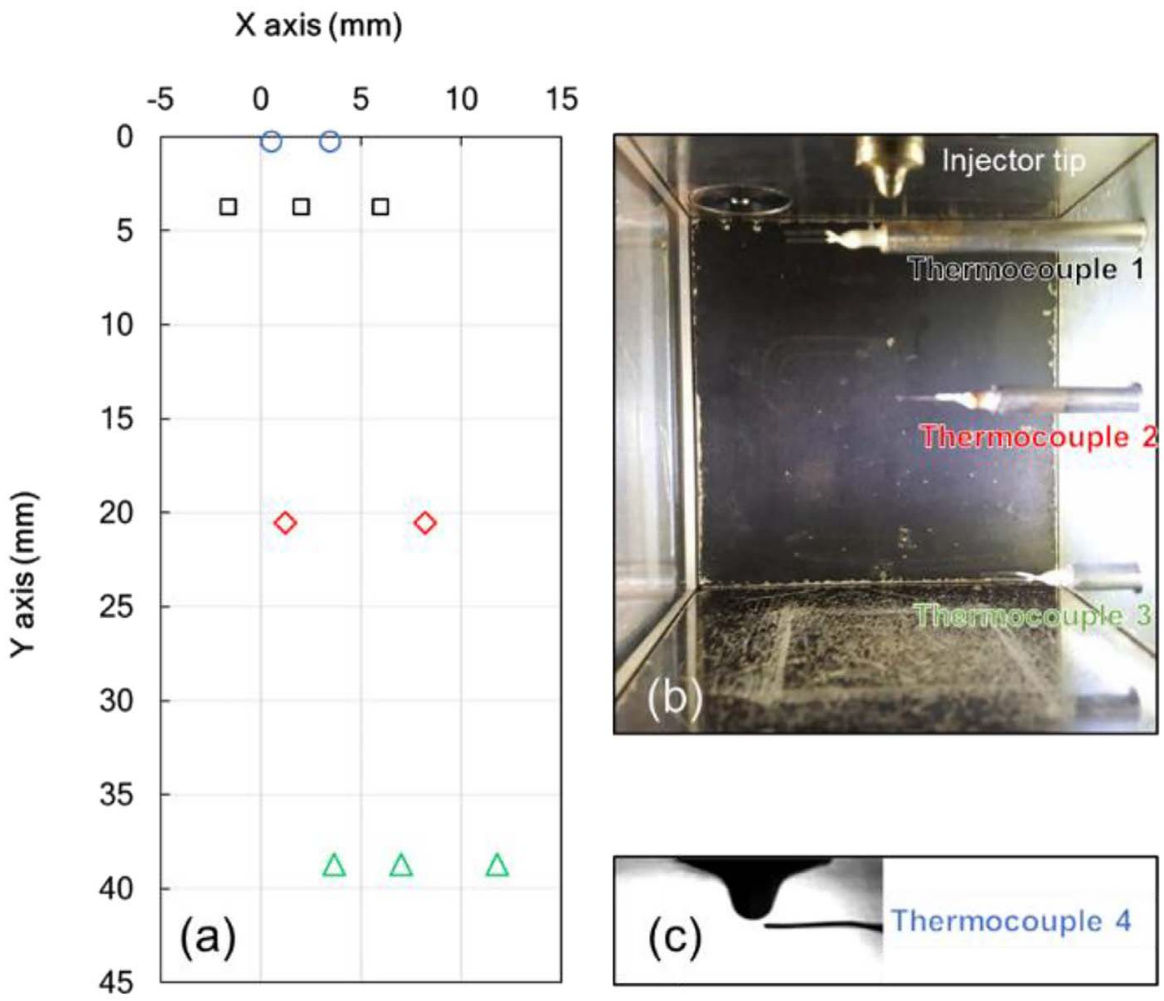

\section{口Thermocouple $1 \diamond$ Thermocouple $2 \Delta$ Thermocouple 3 oThermocouple 4}

Fig. 18. (a) Illustration of thermocouples positions, (b) picture of thermocouples mounted in the center plane of the PPRIME RCM, (c) position of the thermocouple in the near nozzle measurement tests.

the thermocouple junction makes the sensor more robust, while it deteriorates its spatial resolution and time response.

\subsubsection{Gas temperature measurement in PPRIME}

In PPRIME, the temperature is simultaneously measured at three different locations downstream to the injector nozzle as illustrated in Figures 18a and 18b (thermocouple 1-3). Complementary measurements have been performed in the near nozzle area using a further thermocouple (thermocouple 4, Fig. 18c). All thermocouples have a $7.6 \mu \mathrm{m}$ wires and have been designed as recommended in Section 4.2.2. The temperature correction is calculated using equation (6) with a time-resolved velocity from PIV measurements and the $\mathrm{Nu}$ correlation of equation (12). An example of the corrected gas temperatures is presented in Figure 19. The measured temperature is compared to the adiabatic core temperature $T_{\mathrm{c}}$, using the following equation:

$$
\int_{T_{0}}^{T_{\mathrm{c}}} \frac{\gamma}{\gamma-1} \frac{\mathrm{d} T}{T}=\ln \left(\frac{P_{\mathrm{c}}}{P_{0}}\right)
$$

where $T_{0}$ is the initial temperature before compression, $\gamma$ is the heat capacity ratio, $P_{0}$ and $P_{\mathrm{c}}$ are respectively the initial and the compression pressures. This calculated temperature is representative of the maximum temperature in the RCM chamber [23, 25]. The local instantaneous measurements show excellent agreement with this temperature during

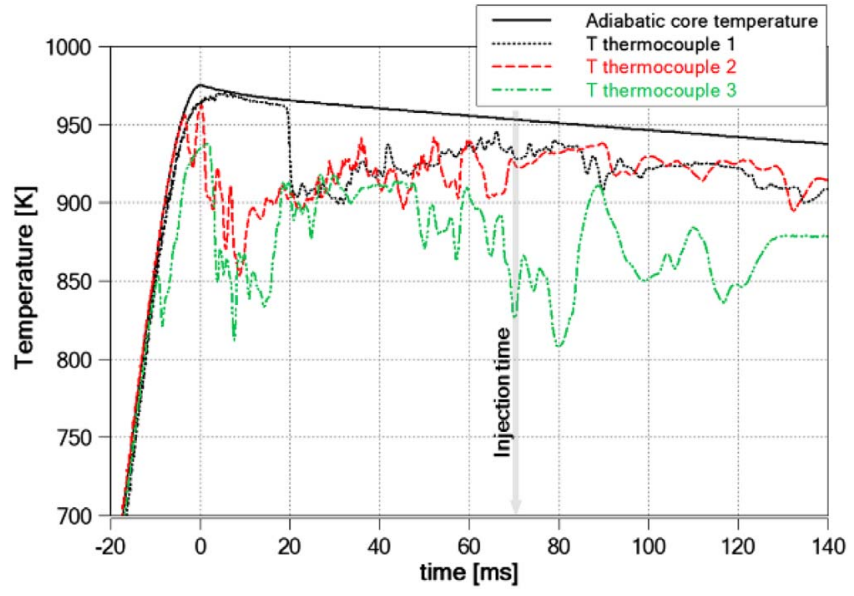

Fig. 19. Illustration of the measured temperature from a single test compared to adiabatic core temperature.

the early stage of compression. In this time range, all sensors are located in the hot adiabatically compressed gas region. This demonstrates that the thermocouples have a relatively fast response and that the correction method is suitable for the current application. At later stages, the cold roll-up vortices generated by the piston motion move toward the upper side of the chamber leading to substantial temperature heterogeneities. As the piston is kept at TDC 

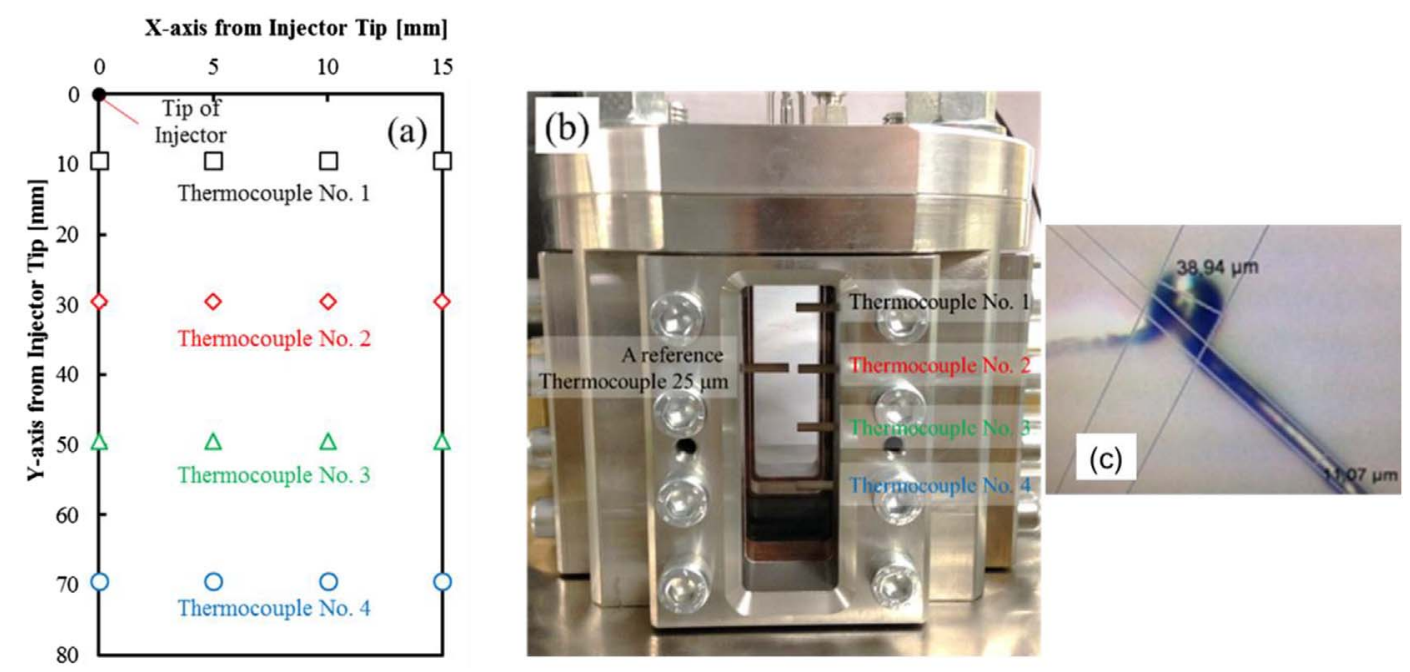

Fig. 20. Location of the temperature measurement in PRISME. Four thin-wire thermocouples of $13 \mu \mathrm{m}$ nominal diameter are used: (a) illustration of measurement positions, (b) picture of thermocouples mounted in the centerline of the NOSE chamber, and (c) picture of the thermocouple junction.

at the end of the compression, the vortices motion dissipates progressively while mixing the hot and colder gases. Thus, the injection timing has been placed at $74 \mathrm{~ms}$ after TDC, when the overall velocity level in the chamber is lower than $1 \mathrm{~m} / \mathrm{s}$ and the temperature distribution is relatively homogeneous. The averaged gas temperature from five repeated tests measured in 10 different locations is $925 \mathrm{~K}$. The standard deviation of the average temperature through the different positions is $18 \mathrm{~K}$.

\subsubsection{Gas temperature measurement in PRISME}

In PRISME, four type K thin-wire thermocouples have been installed in the optical cylinder head of NOSE. The ambient gas temperature is measured at different locations as illustrated in Figures 20a and 20b, where the spatial coordinates are referenced to the injector tip position. The thermocouple wires have a nominal diameter of $13 \mu \mathrm{m}$ approximately. The junction has a spherical shape of approximately $39 \mu \mathrm{m}$ diameter, a picture of the bead is reported in Figure 20c. The temperature correction is calculated with equation (6) and the Nu correlation of Kramers equation (10) using an average constant velocity $(U=0.1 \mathrm{~m} / \mathrm{s}$, estimation based on PIV measurements presented in the Sect. 3.2). An example of ambient temperature measurement with thermocouple no. 2 is illustrated in Figure 21. The correction of measured temperature is significantly higher during the compression and later in the expansion stage. Most likely, this is explained by the important temperature rise/decay rate in these periods. The average and standard deviation of the measured temperature from 10 tests is presented in Figure 21b. Up to $5 \mathrm{~ms}$ after TDC, the temperature is stable. As the temperature starts to decrease, more heterogeneities are observed. In this period of interest (10 ms after TDC), the pressure and density decrease slightly, from 59.8 bar to $59.3 \mathrm{bar}$ and from $22.8 \mathrm{~kg} / \mathrm{m}^{3}$ to $21.7 \mathrm{~kg} / \mathrm{m}^{3}$. The temperature fluctuation in this period is around $1.6 \%$ of the target value.

\subsubsection{Time resolved temperature measurement in the near-nozzle area}

The temperature heterogeneities observed in CVP and RCM vessels are mainly generated by the heat transfer to the walls. In most cases, the injector nozzle protrudes few millimeters inside the vessels and this makes the temperature in the near wall area very important for the interpretation of the spray characterization results.

A thin-wire thermocouple, labeled thermocouple 4 in Figure 18, was placed at $0.3 \mathrm{~mm}$ from the injector nozzle in PPRIME. The temperature is measured during the injection under inert and reactive conditions and compared to temperature measurement without injection (compression test). In inert experiments, the exact position of thermocouple 4 is $(0.3,0.3)$ on the $(x, y)$ coordinates illustrated in Figure 18a. In reactive experiments, the exact position of thermocouple 4 is $(3.5,0.3)$ as the sensor has been pulled away from the nozzle to avoid damaging it during the combustion at the EOI. The comparison of these measurements is presented in Figure 22, where the theoretical maximum temperature (obtained from the pressure measurement and the adiabatic core hypothesis) is also reported. Figure 22a shows that, in the inert case, the temperature significantly decreases immediately after the start of the injection (in average $50 \mathrm{~K}$ lower at the EOI). Considering that the thermocouple is not directly faced to the spray flow and that the temperature decrease is significantly larger than the one indicated by the pressure-derived calculation, it can be concluded that the thermocouple is measuring a local effect. This effect is most likely caused by the colder gases from the boundary layer, which move towards the spray region following the gas-entrainment up to the EOI. The increasing difference between the cases with and without injection observed $20-40 \mathrm{~ms}$ after SOI in inert cases is related to the evaporated fuel, which mixes with the compressed hot gases and generates further temperature heterogeneities that are transported and diffused to the 
(a)

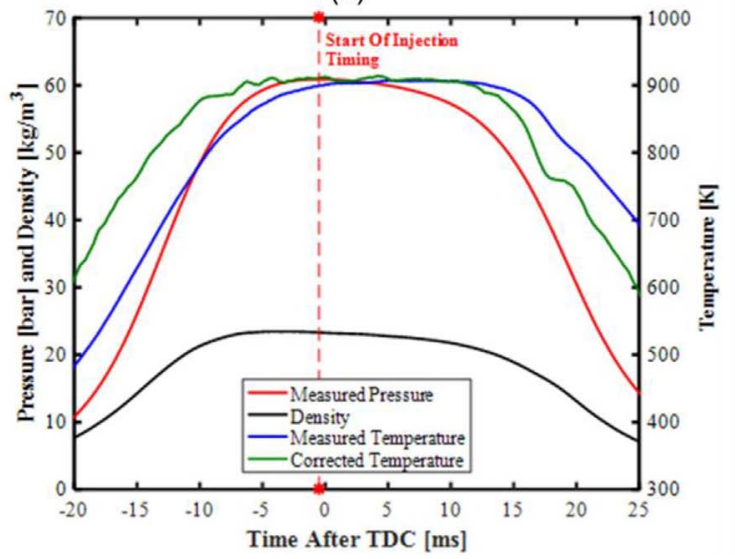

(b)

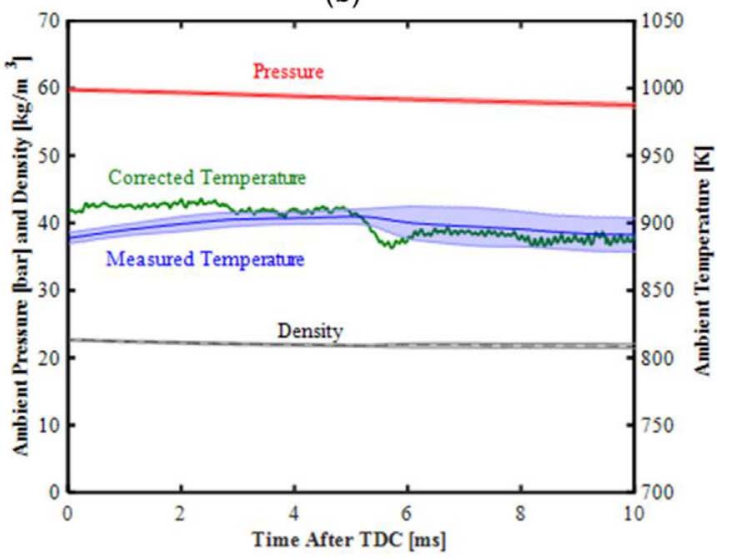

Fig. 21. Illustration of typical temperature profile in PRISME (thermocouple 2): (a) example of density, pressure, and temperature profiles around TDC, (b) average temperature profile at $900 \mathrm{~K}$ target condition, shaded-error bar represents the standard deviation of 10 measurements.

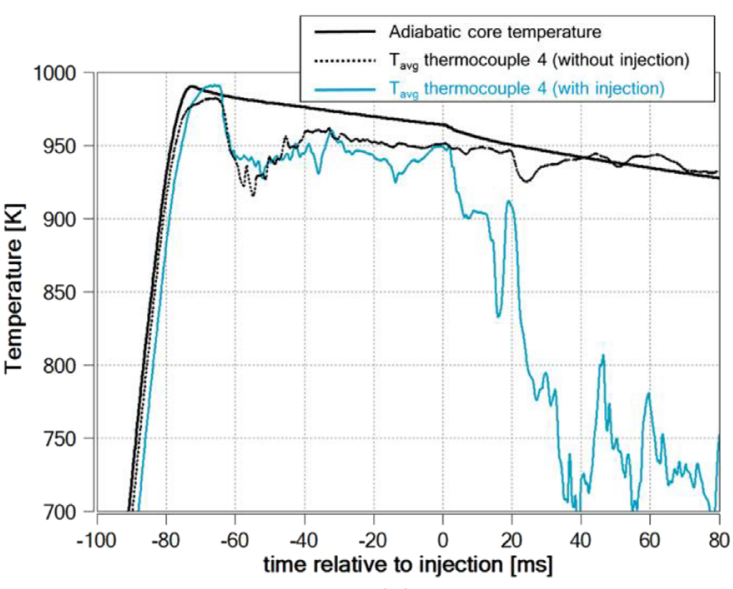

(a)

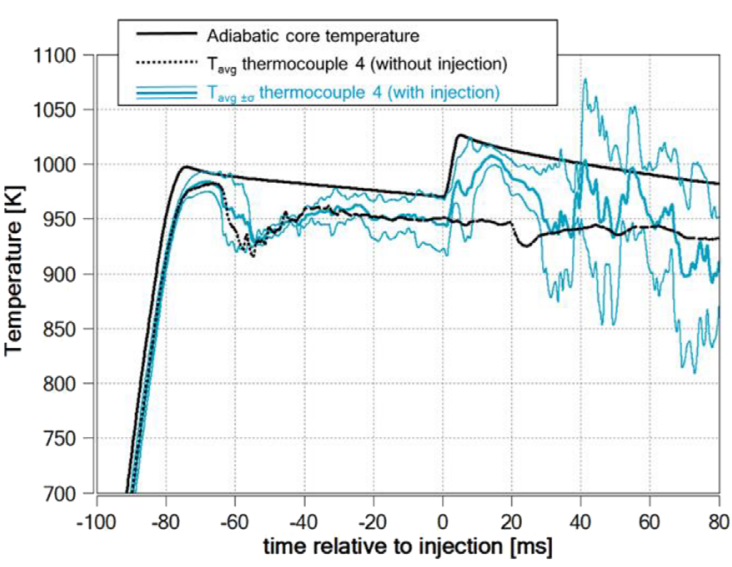

(b)

Fig. 22. Temperature measurement in the near nozzle region: (a) at inert conditions, (b) at reactive conditions.

entire RCM chamber. The temperature of the fuel-air mixture after the complete mixing $(\sim 40 \mathrm{~ms}$ after $\mathrm{SOI})$ is approximately $200 \mathrm{~K}$ lower than the compression test case.

In reactive case, the fuel combustion induces a significant increase of the in-cylinder pressure and temperature. This is clearly demonstrated in Figure $22 \mathrm{~b}$ where the measured temperature increases substantially after the spray ignition. A similar variation is also observed on the pressure-derived temperature. Due to the short ignition delay time and the position of thermocouple 4 in reactive cases, it is not possible to observe the cooling effect of the spray gas-entrainment. Conversely, the temperature of the entrained air is increasing progressively caused by the combustion event up to approximately the EOI. The spray combustion generates further temperature heterogeneities as the hot combustion products are mixed with air and are transported to the entire RCM chamber, which explains measuring higher temperature fluctuations at approximately $40 \mathrm{~ms}$ after SOI. These additional heterogeneities have been observed on Schlieren images (see Fig. A1), which consolidate the above interpretation and explain why the maximum measured temperature is higher than the pressure-derived adiabatic compression temperature at these instants.

ECN vessels have shown different levels of temperature heterogeneities. The standard deviation of the overall measured temperature is around 5\% [30]. These nonhomogeneitied are often not considered in the spray modeling and simulation. So far, more efforts have been spent by the community on the development of adequate chemical kinetic models for the spray. The above temperature measurements during the injection demonstrate that the entrained gas temperature is highly dependent on these heterogeneities. This would influence the spray behavior, 
(a)

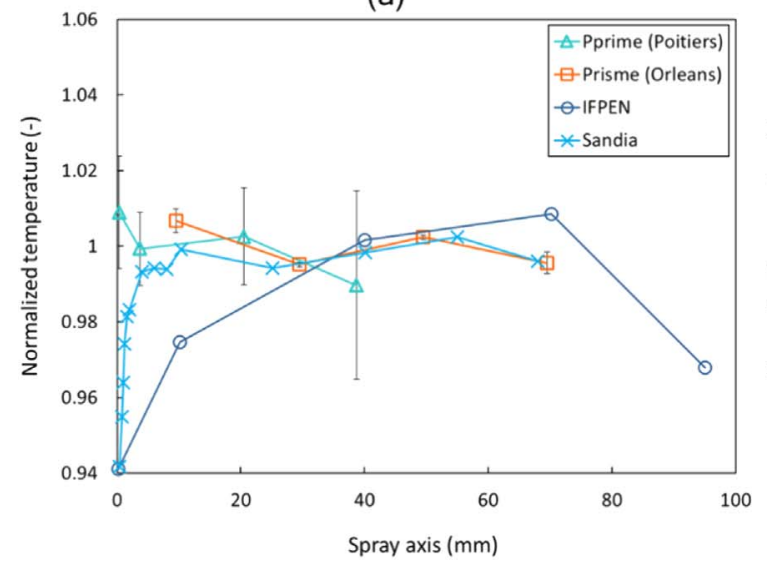

(b)

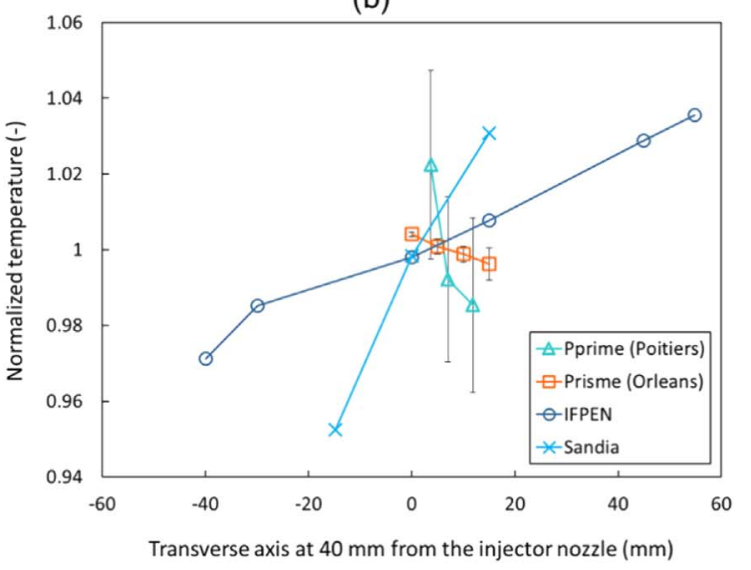

Fig. 23. Comparison of the averaged normalized temperature measured in different ECN facilities: (a) temperature heterogeneity in the spray axis, (b) temperature heterogeneity in the transverse axis at $40 \mathrm{~mm}$ from the injector nozzle. IFPEN and Sandia data from [3].

particularly the ignition delay and the lift-off length, which are sensitive to ambient gas temperature [63]. Thus, it would be more suitable to consider the specific temperature distribution of a vessel in the simulation works aiming to validate new models against experimental data.

\subsubsection{Comparison of temperature homogeneity in ECN spray $A$ vessels}

The characterization of the boundary conditions in different ECN facilities has been reported in $[2,3]$. The ambient gas temperature was pointed out as one of the key parameters that influences the spray behavior, particularly the ignition delay and the lift-off length. The reported temperature heterogeneities in $[2,3]$ is reviewed in Table 6 and compared to RCM results from the present study. In CPF and CVP, lower temperature levels are observed in the near nozzle region. This is illustrated in Figure 23a for IFPEN and Sandia CVP vessels; the temperature is approximately $6 \%$ lower at the nozzle location compared to downstream in the spray axis. RCMs data from PPRIME and PRISME show relatively more homogeneous levels through the spray axis. In PPRIME particular case, the combustion chamber is small (the piston is located at approximately $45 \mathrm{~mm}$ from the injector). Lower temperatures and higher heterogeneities (high test-to-test standard deviation) are observed downstream of the spray axis. In the transverse direction (Fig. 23b), significant temperature gradients are observed in CVP vessels and this is caused by the buoyancy effect [2]. This phenomenon is not observed in RCM vessels as the time constant needed to reach the spray A conditions is an order of magnitude shorter. In addition, the injectors are mounted in the upper side of the RCM chambers. Nevertheless, a small gradient is observed, as the temperature is lower near to the lateral walls, which are located at approximately $25 \mathrm{~mm}$ from the spray axis. Thus, in RCM devices, where the flow pattern is usually axisymmetric, the temperature is higher in the core region. The assessment of temperature heterogeneity through the standard deviation of measured temperature at SOI shows higher levels in the RCM of PPRIME. Most likely, the thermocouples used in PPRIME have a faster time response and thus they are more sensitive to temperature fluctuations. In addition, PPRIME RCM has the lowest wall/body temperature, compared to the other ECN facilities presented in Table 6 .

In most ECN facilities used for spray A experiments, the ambient temperature has been measured with thermocouples. The time response of these sensors is a key parameter that reflects how good the temperature fluctuations can be detected. The sensors should be as fast as possible to capture properly the temperature heterogeneity level in each vessel. Suitable thermocouples would be made of thin-wires (as small as possible) and should have a bare junction. The application of temperature correction is needed to estimate the gas temperature from the junction temperature and thus consider the time response of the sensor. In the current work, it has been demonstrated that a careful design and a proper calculation of the correction factors can provide a relatively accurate measurement. Sheathed thermocouples will not have a time response sufficiently short for temperature fluctuation measurements. The corrected temperature from such sensors should consider the conduction of heat through the sensor body and this reduces substantially the spatial resolution of the measurement. Despite the use of different sensors, all spray A vessels displayed a certain temperature heterogeneity; in region occupied by the spray axis, the temperature deviates of maximum $6 \%$ from the average temperature as a consequence of thermal stratification. Nevertheless, each facility has its own specific heterogeneity level and pattern. It can also be observed that RCM facilities have smaller heterogeneities compared to CVP vessels. This fact is probably related to the short time elapsed between the gas compression and the injection event and the lower maximum temperature. While in CVP vessels, approximately $700 \mathrm{~ms}$ separate the pre-burn event from the SOI. This delay is needed to cool the pre-burn product gases down to the target temperature. 
Table 6. Temperature heterogeneities levels at spray A conditions.

\begin{tabular}{|c|c|c|c|c|}
\hline Institution & Facility & Thermocouple type & $\begin{array}{c}\text { Wall } \\
\text { temperature }\end{array}$ & Heterogeneity level \\
\hline Sandia $[2,3]$ & CVP & $\begin{array}{l}\text { Type-R }\left(d_{\mathrm{w}}=50 \mu \mathrm{m}\right): \\
\mathrm{Pt} / \mathrm{Pt}+13 \mathrm{Rh}\end{array}$ & $461 \mathrm{~K}$ & $\begin{array}{l}\text { Std at } 40 \mathrm{~mm} \text { downstream of spray axis: } 11 \mathrm{~K} \\
45 \mathrm{~K} \text { lower near the injector holder } \\
\pm 1 \% \text { variation in spray axis } \\
\pm 4 \% \text { variation in vertical axis } \pm 15 \mathrm{~mm}\end{array}$ \\
\hline TUE $[2,3]$ & CVP & $\begin{array}{l}\text { Type-R }\left(d_{\mathrm{w}}=50 \mu \mathrm{m}\right) \\
\mathrm{Pt} / \mathrm{Pt}+13 \mathrm{Rh}\end{array}$ & $443 \mathrm{~K}$ & Std at $40 \mathrm{~mm}$ downstream of spray axis: $12 \mathrm{~K}$ \\
\hline IFPEN $[2,3]$ & CVP & $\begin{array}{c}\text { Type-K }\left(d_{\mathrm{w}}=50 \mu \mathrm{m}\right): \\
\mathrm{Ni} / \mathrm{Cr}\end{array}$ & $473 \mathrm{~K}$ & $\begin{array}{l}\text { Std at } 40 \mathrm{~mm} \text { downstream of spray axis: } 14 \mathrm{~K} \\
\pm 2 \% \text { variation in spray axis } \\
< \pm 4 \% \text { variation in vertical axis } \pm 15 \mathrm{~mm}\end{array}$ \\
\hline $\begin{array}{l}\text { Caterpillar } \\
{[2,3]}\end{array}$ & $\mathrm{CPF}$ & $\begin{array}{c}\text { Type-K }\left(d_{\mathrm{w}}=1 \text { and } 3 \mathrm{~mm}\right) \text { : } \\
\mathrm{Ni} / \mathrm{Cr}\end{array}$ & $800 \pm 5 \mathrm{~K}$ & $\begin{array}{l}14 \mathrm{~K} \text { lower near the injector holder }(892-906 \mathrm{~K} \\
\text { within } 3 \mathrm{~mm} \text { from the injector) }\end{array}$ \\
\hline$C M T[2,3]$ & $\mathrm{CPF}$ & Type-K: Ni/Cr & $800 \pm 5 \mathrm{~K}$ & $\begin{array}{l}\text { Std in center volume downstream of spray axis: } \\
2.3 \mathrm{~K}(1 \mathrm{~Hz} \text { logging) } \\
10 \mathrm{~K} \text { lower near the injector holder }(895-905 \mathrm{~K} \\
\text { within } 3 \mathrm{~mm} \text { from the injector) }\end{array}$ \\
\hline $\begin{array}{l}\text { PRISME } \\
\text { (Orleans) }\end{array}$ & $\begin{array}{l}\text { NOSE } \\
(\mathrm{RCM})\end{array}$ & $\begin{array}{c}\text { Type-K }\left(d_{\mathrm{w}}=13 \mu \mathrm{m}\right. \\
\left.d_{\mathrm{j}}=38.9 \mu \mathrm{m}\right)\end{array}$ & $373 \mathrm{~K}$ & $\begin{array}{l}\text { Std at } 30 \mathrm{~mm} \text { downstream to the spray axis: } \\
1 \mathrm{~K} \\
\pm 0.2 \% \text { variation in spray axis } \\
\pm 0.3 \% \text { variation in vertical axis (at } \pm 12 \mathrm{~mm} \\
\text { assuming symmetry) }\end{array}$ \\
\hline $\begin{array}{l}\text { PPRIME } \\
\text { (Poitiers) }\end{array}$ & $\mathrm{RCM}$ & $\begin{array}{c}\text { Type-K }\left(d_{\mathrm{w}}=7.6 \mu \mathrm{m},\right. \\
\left.d_{\mathrm{j}}=\sim 7.6 \mu \mathrm{m}\right)\end{array}$ & $363 \mathrm{~K}$ & $\begin{array}{l}\text { Std at } 40 \mathrm{~mm} \text { downstream to the spray axis: } \\
21 \mathrm{~K} \\
\pm 1.7 \% \text { variation in spray axis } \\
\pm 1.6 \% \text { variation in vertical axis (at } \pm 12 \mathrm{~mm} \\
\text { assuming symmetry) }\end{array}$ \\
\hline
\end{tabular}

Table 7. Summary of the boundary conditions in IFPEN, PPRIME and PRISME vessels.

\begin{tabular}{lccc}
\hline Institution & IFPEN & PPRIME & PRISME \\
\hline Vessel & CVP & RCM & NOSE (RCM) \\
Pressure at SOI & $60.1 \pm 0.2$ (inert) & $47.9 \pm 0.8$ (inert) & $60.9 \pm 0.5$ (inert) \\
& $58.6 \pm 0.2$ (reactive) & $47.8 \pm 0.4$ (reactive) & $59.8 \pm 0.5$ (reactive) \\
Core density at SOI $\left(\mathrm{kg} / \mathrm{m}^{3}\right)$ & $22.86 \pm 0.01$ & $21.1^{*}$ & $22.2^{*}$ \\
Bulk density at SOI $\left(\mathrm{kg} / \mathrm{m}^{3}\right)$ & $24.46^{*}$ & $23 \pm 0.2$ & $24 \pm 0.2$ \\
$T_{\text {core }}$ at SOI $(\mathrm{K})$ & $892 \pm 9$ & $925 \pm 15$ & $904 \pm 5$ \\
$T_{\text {core }} / T_{\text {bulk }}$ & 1.07 & 1.09 & 1.08 \\
Maximum velocity at SOI $(\mathrm{m} / \mathrm{s})$ & $<1$ & $<0.7$ & $<0.2$ \\
\hline
\end{tabular}

${ }^{*}$ Symbol for values deduced from $T_{\text {core }} / T_{\text {bulk }}$ estimation.

In RCM, the cool down is an order of magnitude shorter, thus the total wall heat-losses would be significantly lower.

The measurement of the entrained gas temperature during the injection demonstrates the importance of the near wall gas temperature in the overall spray mixing pro- cess and this highly encourages considering a more realistic temperature field when simulating spray A experiments.

The overall boundary conditions of IFPEN CVP, PPRIME RCM, and PRISME NOSE vessels are summarized in Table 7. The comparison of the measured 
temperature $T_{\text {core }}$ and the calculated average temperature $T_{\text {bulk }}$ confirms that similar global temperature heterogeneities are expected in these devices. However, small differences in $T_{\text {core }}$ at SOI are observed, with PPRIME RCM having the highest value. These differences, caused by both spatial heterogeneity and test-to-test variation, make the estimation of a density representative of the experiments very challenging. The bulk and core densities reported in Table 7 show significantly different values because of the differences between calculated and measured average temperatures. It is worth reminding that considering a constant ambient pressure, the local gas density is expected to have a distribution directly correlated to the local temperature. Thus, it is more relevant to consider this local core density for the definition of a standard target value. This implies that the gas temperature should be characterized extensively in all the locations of the spray region. Particularly, the current work highlights the necessity to measure temperature in the near nozzle and wall regions. The gases in these areas may be entrained to the spray region during the injection and are expected to have a significant effect on the spray behavior.

In addition, due to the difference in gas composition in PPRIME, the target density was reached at pressures significantly lower than in IFPEN CVP and PRISME NOSE vessels. It is worth reminding that the spray A experiments have to be performed at target density, while the pressure is adjusted according to the gas composition used in the vessel. The effect of different pressures and densities on the spray behavior will be investigated in part 2 of the paper [20].

\section{Summary and Conclusion}

In the current paper, the characterization of boundary conditions in different ECN facilities at spray A conditions is reviewed. Particularly, two new vessels based on rapid compression are characterized in details and compared to other facilities employed in ECN community.

The PPRIME RCM and PRISME NOSE have an order of magnitude smaller volume and their body/wall temperatures are $100 \mathrm{~K}$ lower compared to IFPEN CVP. In these rapid compression devices, the injector nozzle temperatures at the time of injection are also lower (approximately $10 \mathrm{~K}$ lower than CVP). The pre-burn event induces a more pronounced increase of the nozzle temperature compared to the rapid compression event of RCM.

The review of gas temperature measurement demonstrated that thermocouple thermometry is competitive when compared to optical diagnostics, being comparatively easier to use and having a very good accuracy. The use of such sensors for the measurement of ambient gas temperature is also reviewed. It is recommended to use bare-bead thermocouples with wires and junction as small as possible to measure properly the temperature fluctuations. Thicker wires lead to a slower time response with the sensor, causing a larger difference between the gas temperature and the measured junction temperature. The methodology used to correct for this deviation has been presented and it has underlined the strong sensitivity of this correction to the characteristic value of the gas velocity through the junction. The correct estimation or measure of this value is therefore fundamental for the accuracy of the temperature measurement.

The comparison of the temperature distribution in the RCM and CVP showed different levels of heterogeneities with different patterns in each vessel. In all facilities, the standard deviation of the overall temperature distribution at SOI is approximately $5 \%$. The gas temperature has been measured during the injection under inert and reactive conditions in PPRIME using a fast response thermocouple. In inert tests, the results demonstrated that colder gases are entrained to the spray-mixing region. The gases in the boundary (wall) layer are likely to influence the spray evaporation and mixing. In reactive tests, the spray combustion induced significant pressure rise and this increased the ambient gas temperature. All these results emphasize the necessity to consider the specific temperature distribution of each vessel when simulating the spray A.

The gas velocity measurements in IFPEN CVP, PPRIME RCM, and PRISME NOSE are presented. Different levels of velocity and turbulence are observed and this is expected to generate differences in the spray behavior between these vessels.

The second part of this work presented in [20], will investigate spray A formation and combustion in the facilities described here. The boundary conditions characterization presented in this work will be the basis for the analysis of the spray results.

Acknowledgments. The authors thank Herve Arlaud and Gildas Lalizel for providing the thin-wire thermocouples to measure the temperature and thank Alain Claverie for providing assistance during the PIV experiments in PPRIME institute. The authors thank Laurent Hermant for helping with the experiments at IFPEN. The authors greatly acknowledge the valuable discussions with Lyle Pickett, Koji Yasutomi, and Russ Fitzgerald when preparing for "ECN Standardization" topic during ECN 5 workshop. The authors acknowledge the National Research Agency (contract ANR-14-CE22-0015-01) for financial support to the ECN-France project. The authors acknowledge Region Centre Val de Loire (CPER 2007-2013 Energies du Futur) and FEDER for financial support to build the experimental set-up in PRISME institute.

\section{References}

1 Engine Combustion Network (2019) [Online] Available from: https://ecn.sandia.gov/.

2 Pickett L., Genzale C., Bruneaux G., Malbec L.M., Hermant L., Christiansen C., Schramm J. (2010) Comparison of diesel spray combustion in different high-temperature, highpressure facilities, SAE Int. J. Engines 3, 2, 156-181.

3 Meijer M., Somers B., Johnson J., Naber J., Lee S.Y., Malbec L.M., Bruneaux G., Pickett L., Bardi M., Payri R., Bazyn T. (2012) Engine Combustion Network (ECN): Characterization and comparison of boundary conditions for different combustion vessels, Atomization Sprays 22, 9, 777-806.

4 Bardi M., Payri R., Malbec L.M., Bruneaux G., Pickett L.M., Manin J., Bazyn T., Genzale C. (2012) Engine Combustion Network: Comparison of spray development, vaporization 
and combustion in different combustion vessels, Atomization Sprays 22, 10, 807-842.

5 Payri R., Molina S., Salvador F.J., Gimeno J. (2004) A study of the relation between nozzle geometry, internal flow and sprays characteristics in diesel fuel injection systems, $K S M E$ Int. J. 18, 1222.

6 Payri R., Salvador F.J., Gimeno J., de-la-Morena J. (2009) Effects of nozzle geometry on direct injection diesel engine combustion process, Appl. Therm. Eng. 29, 10, 2051-2060.

7 Kastengren A.L., Tilocco F.Z., Powell C.F., Manin J., Pickett L.M., Payri R., Bazyn T. (2012) Engine Combustion Network (ECN): Measurements of nozzle diameter and hydraulic behavior of diesel sprays, Atomization Sprays 22, 12, 1011-1052.

8 Bardi M., Bruneaux G., Malbec L.M. (2016) Study of ECN injectors' behavior repeatability with focus on, in: $S A E$ Technical Paper 2016-01-0845.

9 Payri R., Garcia-Oliver J.M., Bardi M., Manin J. (2012) Fuel temperature influence on diesel sprays in inert and reacting conditions, Appl. Therm. Eng. 35, 185-195.

10 Meijer M., Galle J., Somers L.M.T., Griensven J.G.H., Verhelst S. (2013) High-speed characterization of ECN spray A using various diagnostic techniques, SAE Int. J. Engines 6 , $2,1238-1248$.

11 Nesbitt J.E. (2011) Diesel spray mixing limited vaporization with non-ideal and multi-component fuel thermophysical property effects, Michigan Technological University, Houghton, MI.

12 Zhao L. (2018) An experimental and computational study of fuel spray interaction: Fundamentals and engine applications, Michigan Technological University, Houghton, MI.

13 Pei Y., Davis M.J., Pickett L.M., Soma S. (2015) Engine Combustion Network (ECN): Global sensitivity analysis of Spray A for different combustion vessels, Combust. Flame 162, 2337-2347.

14 Nesbitt J.E., Johnson S.E., Pickett L.M., Siebers D.L., Lee S.Y., Naber J.D. (2011) Minor species production from lean premixed combustion and their impact on auto-ignition of diesel surrogates, Energy Fuels 25, 3, 926-936.

15 Payri R., Vieraa J.P., Wang H., Malbec L. (2016) Velocity field analysis of the high density, high pressure diesel spray, Int. J. Multiph. Flow 80, 69-78.

16 Malbec L.M., Bruneaux G. (2010) Study of air entrainment of multi-hole diesel injection by particle image velocimetry effect of neighboring jets interaction and transient behavior after end of injection, SAE Int. J. Engines 3, 1, 107-123.

17 Sphicas P., Pickett L., Skeen S., Frank J. (2017) ECN experimental database [Online]. Available from: https://ecn.sandia. gov/cvdata/assets/datafiles/velocity/SprayAambient6.xlsx.

18 Pei Y., Som S., Garcia-Oliver J.M. (2014) Bridging the gap: How spray details affect combustion [Online]. Available from: https://ecn.sandia.gov/wp-content/uploads/2014/12/ ECN3_BridgeTheGap.pptx.

19 Pastor J., Garcia-Oliver J.M., Garcia A., Zhong W., Mico C., Xuan T. (2017) An experimental study on diesel spray injection into a non-quiescent chamber, SAE Int. J. Fuels Lubricants 10, 2, 394-406.

20 Hespel C., Ben Houidi M., Ajrouche H., Foucher F., Haidous Y., Moreau B., Nilaphai O., Rousselle C., Bellenoue M., Claverie A., Sotton J., Strozzi C., Bardi M., Bruneaux G., Malbec L.-M. (2020) Characterization of the ECN spray A in different facilities. Part 2: Spray vaporization and combustion, Oil Gas Sci. Technol. - Rev. IFP Energies nouvelles. Article submitted.
21 Strozzi C., Sotton J., Mura A., Bellenoue M. (2008) Experimental and numerical study of the influence of temperature heterogeneities on self-ignition process of methane-air mixtures in a rapid compression machine, Combust. Sci. Technol. 180, 10-11, 1829-1857.

22 Strozzi C., Mura A., Sotton J., Bellenoue M. (2012) Experimental analysis of propagation regimes during the autoignition of a fully premixed methane-air mixture in the presence of temperature inhomogeneities, Combust. Flame 159, 11, 3323-3341.

23 Ben-Houidi M., Sotton J., Bellenoue M. (2016) Interpretation of auto-ignition delays from RCM in the presence of temperature heterogeneities: Impact on combustion regimes and negative temperature coefficient behavior, Fuel 186, 476-495.

24 Ben-Houidi M., Sotton J., Claverie A., Strozzi C., Bellenoue M. (2016) Application of high-speed PIV and Toluene PLIF techniques to study aerodynamics and thermal stratification inside a flat piston rapid compression machine, in: 18th International Symposium on the Application of Laser and Imaging Techniques to Fluid Mechanics, Lisbon, Portugal.

25 Ben-Houidi M., Sotton J., Bellenoue M., Strozzi C. (2019) Effects of low temperature heat release on the aerodynamics of a flat piston rapid compression machine: Impact on velocity and temperature fields, Proc. Combust. Inst. 37, 4, 4777-4785.

26 Nilaphai O., Hespel C., Moreau B., Contino F., Bourgeois N., Chanchaona S., Foucher F., Mounaïm-Rousselle C. (2016) New high-pressure and high-temperature chamber for diesel spray characterization, in: 27th Annual Conference on Liquid Atomization and Spray Systems, Brighton, UK.

27 Nilaphai O. (2018) Vaporization and combustion processes of alcohols and Acetone-Butanol-Ethanol (ABE) blended in n-dodecane for high pressure-high temperature conditions: Application to compression ignition engine, HAL Id: tel02095626, Orleans, France.

28 Eagle W.E., Musculus M.P.B., Malbec L.M., Bruneaux G. (2014) Measuring transient entrainment rates of a confined vaporizing diesel jet, in:ILASS Americas 26th Annual Conference on Liquid Atomization and Spray Systems, Portland, OR.

29 Sciacchitano A., Scarano F., Wieneke B. (2012) Multi-frame pyramid correlation for time-resolved PIV, Exp. Fluids 53, 1087-1105.

30 Ben-Houidi M., Yasutomi K., Fitzgerald R. (2017) ECN5 proceedings [Online]. Available from: https://ecn.sandia. gov/workshop/ECN5/ECN_5_Standardization_of_Spray_ A $\mathrm{V}$ final.pdf.

31 Childs P.R.N., Greenwood J.R., Long C.A. (2000) Review of temperature measurement, Rev. Sci. Instrum. 71, 8, 29592978.

32 Griffiths J.F., MacNamara J.P., Sheppard C.G.W., Turton D.A., Whitaker B.J. (2002) The relationship of knock during controlled autoignition to temperature inhomogeneities and fuel reactivity, Fuel 81, 2219-2225.

33 Strozzi C., Sotton J., Mura A., Bellenoue M. (2009) Characterization of a two dimensional temperature field within a rapid compression machine using a toluene planar laser induced fluorescence imaging technique, Meas. Sci. Technol. 20, 125403.

34 Tran K.H., Guibert P., Morin C., Bonnety J., Pounkin S., Legros G. (2015) Temperature measurements in a rapid compression machine using anisole planar laser-induced fluorescence, Combust. Flame 162, 10, 3960-3970. 
35 Desgroux P., Gasnot L., Sochet L. (1995) Instantaneous temperature measurement in a rapid-compression machine using laser rayleigh scattering, Appl. Phys. B 61, 69-72.

36 Clarkson J., Griffiths J.F., Macnamara J.P., Whitaker B. (2001) Temperature fields during the development of combustion in a rapid compression machine, Combust. Flame 125, 3, 1162-1175.

37 Miles R.B., Lempert W.R., Forkey J.N. (2001) Laser Rayleigh scattering, Meas. Sci. Technol. 12, R33-R51.

38 Uddi M., Das A.K., Sung C. (2012) Temperature measurements in a rapid compression machine using Mid-IR H2O absorption spectroscopy near $7.6 \mu \mathrm{m}$, Appl. Opt. 51, 22, 5464-5476.

39 Das A.K., Uddi M., Sung C. (2012) Two-line thermometry and $\mathrm{H} 2 \mathrm{O}$ measurement for reactive mixtures in rapid compression machine near $7.6 \mu \mathrm{m}$, Combust. Flame 159, 12, 3493-3501.

40 Nasir E.F., Farooq A. (2017) Time-resolved temperature measurements in a rapid compression machine using quantum cascade laser absorption in the intrapulse mode, Proc. Combust. Inst. 36, 4453-4460.

41 Förster F., Crua C., Davy M., Ewart P. (2019) Temperature measurements under diesel engine conditions using laser induced grating spectroscopy, Combust. Flame 199, 249-257.

42 Förster F.J., Crua C., Davy M., Ewart P. (2017) Time-resolved gas thermometry by laser-induced grating spectroscopy with a high-repetition rate laser system, Exp. Fluids 58, 87.

43 Patton R.A., Gabet K.N., Jiang N., Lempert W.R., Sutton J.A. (2012) Multi-kHz temperature imaging in turbulent non-premixed flames using planar Rayleigh scattering, Appl. Phys. B: Lasers Opt. 108, 377-392.

44 Miller J.D., Slipchenko M.N., Meyer T.R., Stauffer H.U., Gord J.R. (2010) Hybrid femtosecond/picosecond coherent anti-Stokes Raman scattering for high-speed gas-phase thermometry, Opt. Lett. 35, 14, 2430-2432.

45 Sun B.N., Chang J., Lian J., Wang Z.L., Lv G.P., Liu X.Z., Wang W.J., Zhou S., Wei W., Jiang S., Liu Y.N., Luo S., Liu X.H., Liu Z., Zhang S.S. (2013) Accuracy improvement of Raman distributed temperature sensors based on eliminating Rayleigh noise impact, Opt. Commun. 306, 117-120.

46 Heitor M.V., Moreira A.L.N. (1993) Thermocouples and sample probes for combustion studies, Prog. Energy Combust. Sci. 19, 259-278.

47 Paranthoen P., Lecordier J. (1996) Mesures de temperature dans les ecoulements turbulents, Rev. Gen. Therm. 35, 283-308.

48 Paranthoen P., Lecordier J., Petit C., Gajan P. (1983) Survey and Recent developments of frequency response studies of cold wires and fine wire thermocouples in turbulent heated flow, in: Eighth Austalasian Fluid Mechanics Conference, University of Newcastle, N.S.W.

49 Tagawa M., Kato K., Ohta Y. (2005) Response compensation of fine wire temperature sensors, Rev. Sci. Instrum. 76, 094904.

50 Arwatz G., Bahri C., Smits A.J., Hultmark M. (2013) Dynamic calibration and modeling of a cold wire for temperature measurement, Meas. Sci. Technol. 24, 125301.

51 Dupont A., Paranthoen P., Lecordier J.C., Gajan P. (1984) Influence of temperature on the frequency response of finewire thermocouples over the range $(300 \mathrm{~K}-800 \mathrm{~K})$ in airflows, J. Phys. E: Sci. Instrum. 17, 808-812.

52 Thierry L. (2006) Microsondes thermoelectriques, Techniques de l'ingenieur $\mathbf{R} 2 \mathbf{7 6 5}, 1-24$.

53 Pitts W., Braun E., Peacock R., Mitler H., Johnsson E., Reneke P., Blevins L. (2003) Temperature uncertainties for bare-bead and aspirated thermocouple measurements in fire environments, in: Gritzo L., Alvares N. (eds), Thermal measurements: The foundation of fire standards, ASTM International, West Conshohocken, PA, pp. 3-15.

54 Kent J.H. (1970) A noncatalytic coating for platinumrhodium thermocouples, Combust. Flame 28, 301.

55 Madson J.M., Theby E.A. (1983) SiO2 coated thermocouples, Combust. Sci. Technol. 36, 205-209.

56 Caldwell F.R. (1962) Thermocouple materials, National Bureau of Standards Monograph No. 40, Washington, DC.

57 Betchov R. (1948) L'influence de la conduction thermiquesur les anenometres a fils chauds, Proc. Koninklijke Nederlandse Akademie van Wetenschappen 51, 721.

58 Corrsin S. (1963) Turbulence: experimental methods, Encycl. Phys. 3, 8, 524-590.

59 Collis D.C., Williams M.J. (1959) Two dimensional convection from heated wires at low Reynolds numbers, J. Fluid Mech. 6, 4, 357-384.

60 Collis D.C., Williams M.J. (1959) Two-dimensional convection from heated wires at low Reynolds Numbers, J. Fluid Mech. 6, 4, 357-384.

61 Kramers H. (1946) Heat transfer from spheres to flowing media, Physica 12, 61-80.

62 Churchill S.W., Bernstein M. (1977) A correlating equation for forced convection from gases and liquids to a circular cylinder in crossflow, J. Heat Trans. 99, 300-306.

63 Pei Y., Som S., Garcia-Oliver J.M. (2014) ECN3 proceedings [Online]. Available from: https://ecn.sandia.gov/wpcontent/uploads/2014/12/ECN3_BridgeTheGap.pptx. 


\section{Appendix}

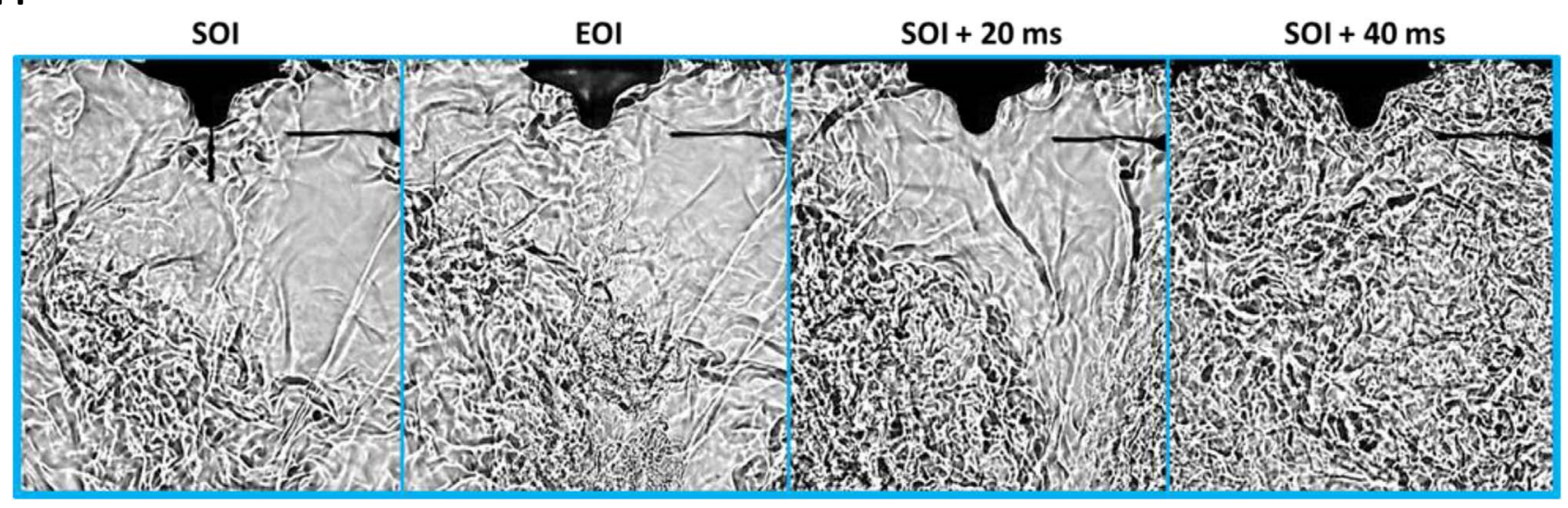

Fig. A1. Raw Schlieren images showing thermocouple 4 position and the qualitative density gradients in the RCM chamber at different instants: test condition of Figure $22 \mathrm{~b}$. 